\title{
EXPLORAÇÃO TRADICIONAL E PLANEJADA NUMA ÁREA DA AMAZÔNIA ORIENTAL: FITOSSOCIOLOGIA E DIVERSIDADE DE ESPÉCIES ARBÓREAS
}

\author{
LAERTE NOGUEIRA DA SILVA \\ Engenheiro Florestal
}

Orientador: Prof. Dr. JOÃO LUIS FERREIRA BATISTA

Dissertação apresentada à Escola Superior de Agricultura "Luiz de Queiroz", Universidade de São Paulo, para obtenção do título de Mestre em Recursos Florestais, Área de Concentração: Recursos Florestais, com opção em Manejo de Florestas de Produção.

PIRACICABA

Estado de São Paulo - Brasil

Fevereiro -2002 


\section{LAERTE NOGUEIRA DA SILVA. EXPLORAÇÃO TRADICIONAL E PLANEJADA NUMA ÁREA DA AMAZÔNIA ORIENTAL: FITOSSOCIOLOGIA E DIVERSIDADE DE ESPÉCIES ARBÓREAS.}

\begin{tabular}{|c|c|c|c|c|}
\hline p. & item & linha & onde se lê & leia-se \\
\hline 05 & 2 & $\begin{array}{l}\text { décima } \\
\text { primeira }\end{array}$ & ... devastamento & ... devastação \\
\hline 08 & 2 & $\begin{array}{l}\text { décima } \\
\text { terceira }\end{array}$ & ... stresse & ... estresse \\
\hline 08 & 2 & vigésima & ... stresse & ... estresse \\
\hline 13 & 3.2 .1 & terceira & $\ldots \mathrm{DAP} \geq 25 \mathrm{~cm}$ & $\ldots 10 \mathrm{~cm} \leq \mathrm{DAP}<25 \mathrm{~cm}$ \\
\hline 14 & 3.3 & $\begin{array}{l}\text { vigésima } \\
\text { sexta }\end{array}$ & $\ldots$ ou parcelas, de $25 \mathrm{~m} \mathrm{X} 350 \mathrm{~m}$ & ... ou parcelas, de $25 \mathrm{~m}$ X 350m (Figura 1). \\
\hline 18 & 3.5 & $\begin{array}{l}\text { décima } \\
\text { segunda }\end{array}$ & ... numa comunidade ou população & ... numa comunidade. \\
\hline 23 & 4.1 & $\begin{array}{l}\text { décima } \\
\text { nona }\end{array}$ & ... após a exploração ... & ... após $1993 \ldots$ \\
\hline 25 & 4.2 .1 & $\begin{array}{l}\text { vigésima } \\
\text { terceira }\end{array}$ & Tabela 4. Densidade absoluta ... & Tabela 4. Densidade absoluta $\left(\mathrm{n}^{\circ}\right.$ de ind. $\left.\mathrm{ha}^{-1}\right) \ldots$ \\
\hline 33 & 4.2 .2 & $\begin{array}{l}\text { décima } \\
\text { sexta }\end{array}$ & ... mais dificultoso ... & ... mais difícil ... \\
\hline 33 & 4.2 .2 & $\begin{array}{l}\text { décima } \\
\text { oitava }\end{array}$ & ... pela aplicabilidade ... & ... pela aplicação ... \\
\hline 38 & 4.3 & $\begin{array}{l}\text { vigésima } \\
\text { sexta }\end{array}$ & Organizando as cifras: & Organizando os valores: \\
\hline 40 & 4.3 & segunda & Organizando as cifras: & Organizando os valores: \\
\hline 41 & 4.5 & sétima & $\ldots$ as Figuras $12,13,14$ mostram & $\ldots$ as Figuras 12 e 13 mostram ... \\
\hline 41 & 4.5 & sexta & $\begin{array}{l}\text {... perdas na diversidade numa } \\
\text { magnitude significante ao longo } \\
\text { do tempo. }\end{array}$ & $\begin{array}{l}\text {... perdas na diversidade ao longo } \\
\text { do tempo. }\end{array}$ \\
\hline 43 & 4.5 & $\begin{array}{l}\text { décima } \\
\text { segunda }\end{array}$ & ... a diversidade das Famílias ... & $\ldots$ a diversidade do ambiente ... \\
\hline 44 & 4.5 & $\begin{array}{l}\text { décima } \\
\text { quarta }\end{array}$ & ... espécies recrutadas ... & ... espécies selecionadas ... \\
\hline 44 & 4.5 & $\begin{array}{l}\text { décima } \\
\text { quinta }\end{array}$ & ... nesse recrutamento ... & ... nessa seleção ... \\
\hline
\end{tabular}

Eliminar parágrafo:

p. item onde se lê

$43 \quad 4.5$ Portanto, foi observado ... 


\section{Dados Internacionais de Catalogação na Publicação (CIP) DIVISÃO DE BIBLIOTECA E DOCUMENTAÇÃO - ESALQ/USP}

Silva, Laerte Nogueira da

Exploração tradicional e planejada numa área da Amazônia Oriental : fitossologia e diversidade de espécies arbóreas / Laerte Nogueira da Silva. - - Piracicaba, 2002.

$72 \mathrm{p}$.

Dissertação (mestrado) - - Escola Superior de Agricultura Luiz de Queiroz, 2002. Bibliografia.

1. Amazônia Oriental 2. Comunidades vegetais 3. Exploração florestal 4.

Variedades vegetais I. Título

CDD 634.98

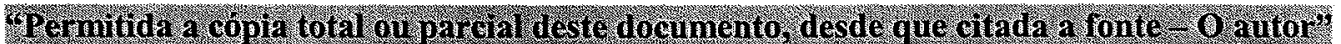


Aos meus pais pela oportunidade de estar nesse mundo para cumprir a missão terrena. Aos meus avós Hilário e Nené pelo maravilhoso tempo em que estivemos por perto. $\mathrm{E}$ as minhas duas maravilhosas mães Olga e Sérgia, dedico. 


\section{AGRADECIMENTOS}

a João Batista, pela apresentação a um mundo novo de informações, pela orientação, críticas e amizade;

ao CNPq pela bolsa concedida;

ao Edson do Imazon por oferecer os dados e possibilitar a análise dessa vegetação em Paragominas - PA;

ao meu irmão Fábio pelo apoio moral e financeiro nos momentos difíceis;

aos meus irmãos: Ulisses, Gil, Rita e Hercílio por sua existência;

aos meus sobrinhos Vinícius, Maria Vitória e Lucas pela possibilidade de enxergar o amor de uma outra forma;

ao meu grande amigo Fábio (japa) pela insistência, tolerância, companheirismo e conselhos de vida;

aos meus tios, primos, cunhadas, cunhado e a essa grandiosa e alegre família pela união, fé e luta em seus ideais;

a Anna Júlia, Lana, Bia,, Carlinha, Thais, Eva, Vivianes e demais companheiros da turma de mestrado/2000, pela amizade, discussões, brigas e sorrisos;

ao Fábio Sgarbi, Maurício, Eliza, Flaviana, Mario, Luiz, Clarissa e demais colegas do LMQ pelo convívio e respeito;

ao Jeferson (Jeff) e Ivo pela incansável presteza, dedicação e amizade;

ao Dr. Gil Vieira e Dr. Paulo de Tarso pelo grandioso apoio em minha vinda à Piracicaba e a Solange (serviço social - ESALQ) e Prof. Natal pelo apoio e atenção nos primeiros dias em terra nova;

aos colegas da "vila": Gean, Antônio, Dori, Cláudio, Santiago, Norberto, Genelício, Geni, Bibiana e outros mais, pela chance de aprender a viver em grupo;

a Noemi pelos momentos especiais de convívio, grandiosa amizade e a oportunidade de perceber o espanhol com muito mais naturalidade. 


\section{SUMÁRIO}

Página

LISTA DE FIGURAS vii

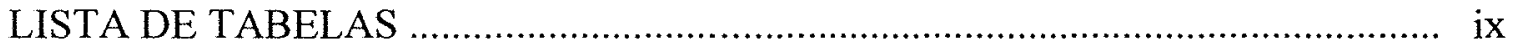

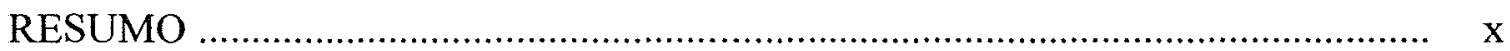

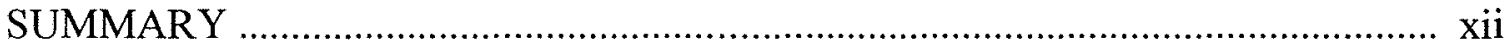

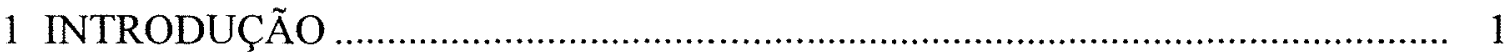

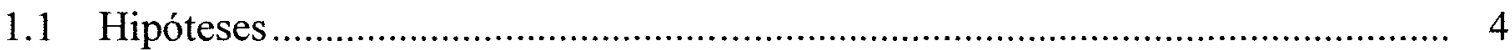

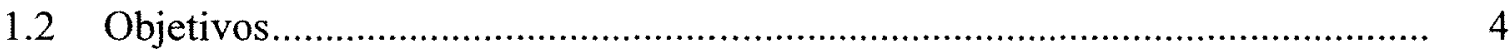

2 REVISÃO DE LITERATURA …...................................................................... 5

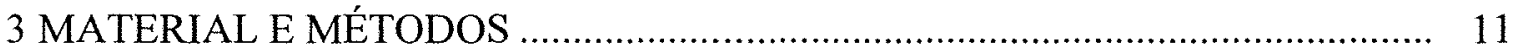

3.1 Caracterização da Área de Estudo .................................................................. 11

3.1.1 Município de Paragominas - PA ................................................................... 11

3.2 Atividades desenvolvidas e coleta de dados ................................................. 12

3.2.1 Sistema de Exploração Planejada ...................................................................... 12

3.2.2 Sistema de Exploração Tradicional ................................................................ 13

3.3 Descrição do Sistema de Amostragem ........................................................... 14

3.4 Parâmetros Fitissociológicos ........................................................................ 16 
3.5 Índices de Diversidade............................................................................. 18

3.5.1 Índice de Shannon............................................................................... 18

3.5.2 Índice de Simpson................................................................................. 19

3.6 Monitoramento dos Tratamentos ................................................................ 19

4 RESULTADOS E DISCUSSÃO ........................................................................ 21

4.1 Distribuição dos Indivíduos nos tratamentos................................................. 21

4.2 Parâmetros Fitossociológicos …………..................................................... 25

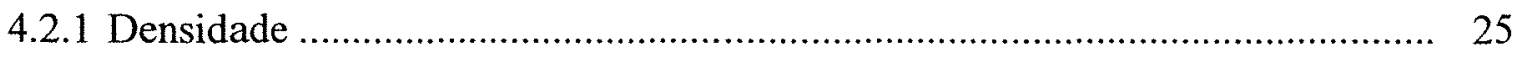

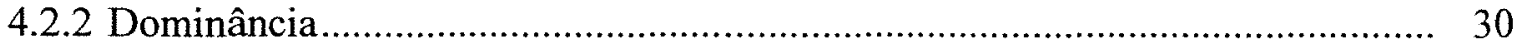

4.2.3 IVC - Í ndice de Valor de Cobertura …….................................................... 33

4.3 Perdas na Exploração Tradicional ................................................................... 38

4.4 Perdas na Exploração Planejada ................................................................... 39

4.5 Diversidade e estrutura comunistária nos tratamentos estudados...................... 41

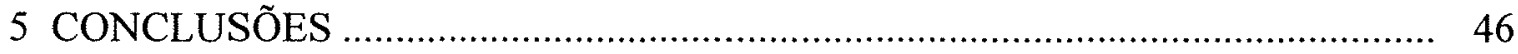

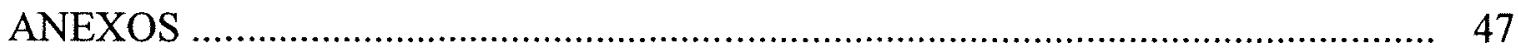

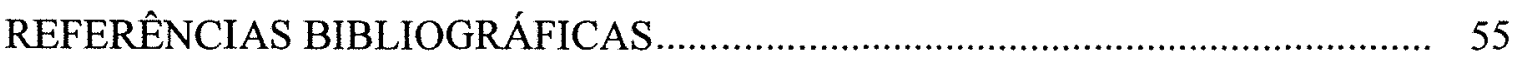




\section{Lista de Figuras}

Página

1 Distribuição das parcelas amostrais nos blocos permanentes. Sendo: o bloco superior relativo à Área de Proteção Permanente, o bloco a baixo e à esquerdà à Área submetida a Exploração Tradicional, e o bloco a baixo e à direita relativo a Área submetida a Exploração Planejada . . . . . . . 15

2 Mapa de Distribuição das espécies, em todos tratamentos, com seus respectivos intervalos diamétricos. . . . . . . . . . . . . . 21

3 Gráfico Quantil-Quantil para o diâmetro das árvores entre o ano de 1993 e os anos $(1994,1995,1996,1998,2000)$ posteriores ao processo de extração na Área de Exploração Tradicional . . . . . . . . . . . . . . . . 27

4 Gráfico Quantil-Quantil para o diâmetro das árvores no ano de 1993 e os anos $(1994,1995,1996,1998,2000)$ posteriores ao processo de extração na Área de Exploração Planejada . . . . . . . . . . . . . . . . . . . 28

5 Gráfico Quantil-Quantil para o diâmetro das árvores no ano de 1993 e os $\operatorname{anos}(1994,1995,1996,1998,2000)$ posteriores ao processo de extração na Área de Proteção Permanente . . . . . . . . . . . . . . . . . . 29

6 Curva de Whittaker para DOA na Área de Exploração Planejada . . . 30

7 Curva de Whittaker para DOA na Área de Exploração Tradicional . . 31

8 Curva de Whittaker para DOA na Área de Proteção Permanente . . . . 32

9 Rank de IVC das 30 espécies de maior atributo desse parâmetro na Área de Proteção Permanente, nos anos de 1993, 1994, 1995, 1996, 1998, $2000 \quad 34$

10 Rank de IVC das 30 espécies de maior atributo desse parâmetro na Área de Exploração Planejada, nos anos de 1993, 1994, 1995, 1996, 1998, 200035 
11 Rank de IVC das 30 espécies de maior atributo desse parâmetro na Área de Exploração Tradicional, nos anos de 1993, 1994, 1995, 1996, 1998, 200037

12 Indices de diversidade de Simpson para os três tratamentos, utilizando dominância (acima) e densidade (a baixo) como parâmetros . . . . . . . 42

13 Índices de diversidade de Shannon para os três tratamentos, utilizando dominância (acima) e densidade (a baixo) como parâmetros . . . . . . . 43 


\title{
Lista de Tabelas
}

\author{
Página
}

1 Número de ind no tratamento Área de Exploração Tradicional pelos diferentes anos e classes diamétricas . . . . . . . . . . . . . . . . 22

2 Número de ind no tratamento Área de Exploração Planejada pelos diferentes anos e classes diamétricas . . . . . . . . . . . . . . . . . 23

3 Número de ind no tratamento Área de Proteção Permanente pelos diferentes anos e classes diamétricas . . . . . . . . . . . . . . 24

4 Densidade absoluta nos diferentes tratamentos pelos diferentes anos . . 25

5 Dominância absoluta nos diferentes tratamentos pelos diferentes anos . . 32

6 Indice de Shannon - Winer para os tratamentos em todos os anos de medições . . . . . . . . . . . . . . . . . . . 44

7 Índice de Simpson para os tratamentos em todos os anos de medições . . 45 


\title{
EXPLORAÇÃO TRADICIONAL E PLANEJADA NUMA ÁREA DA AMAZÔNIA ORIENTAL: FITOSSOCIOLOGIA E DIVERSIDADE DE ESPÉCIES ARBÓREAS
}

\author{
Autor: LAERTE NOGUEIRA DA SILVA \\ Orientador: Prof. Dr. JOÃO LUIS FERREIRA BATISTA
}

\section{RESUMO}

O impacto da exploração florestal sobre a massa remanescente em área da Fazenda Agrossete, localizada no município de Paragominas, foi avaliado com base nos dados de 3 (três) blocos permanentes de 24.5 ha, estabelecidos em 1993 em três áreas: área de preservação permanente, área submetida a exploração tradicional e área submetida a exploração planejada. Essas áreas totalizam 210 ha, subdivididos em 30 ha, 105 ha e 75 ha respectivamente. Foi feito o inventário florestal em 1993, antes das intervenções realizadas no mesmo ano, com a identificação de todas as espécies arbóreas de valor comercial com $\mathrm{DAP} \geq 10 \mathrm{~cm}$ e todas as outras com DAP $\geq$ $25 \mathrm{~cm}$. O procedimento adotado na área de exploração tradicional foi o de derrubada das árvores sem critérios técnicos, e na de exploração planejada foram utilizadas as técnicas de manejo florestal desenvolvidas pelo IMAZON (Instituto do Homem e Meio Ámbiente da Amazônia). Avaliando-se o impacto dos procedimentos de 
exploração sobre os atributos fitossociológicos e de diversidade de espécies arbóreas na diversificada composição florística observada em ambos tratamentos, compostos de 167 espécies na área de proteção permanente, 188 espécies na área de exploração planejada e 116 na área de exploração tradicional. Onde os índices de Shannon e Simpson apontaram baixa ou nenhuma diferença na diversidade florística entre os tratamentos nos diferentes anos. 


\title{
TRADITIONAL AND PLANNED HARVEST IN A FOREST OF AMAZON EASTERN: PHYTOSOCIOLOGY AND TREE SPECIES DIVERSITY
}

\author{
Author: LAERTE NOGUEIRA DA SILVA \\ Adviser: Prof. Dr. JOÃO LUIS FERREIRA BATISTA
}

\section{SUMMARY}

The forest harvesting impact upon the remaining area at Agrossete Farm, located in the city of Paragominas - in the state of Pará, evaluated on 3 permanent blocks of 245 ha, established in 1993 in three areas of permanent preservation, a submitted area of traditional harvest and an area of planned harvest. Those areas totalize $210 \mathrm{ha}$, subdivided in $30 \mathrm{ha}, 105 \mathrm{ha}$ and 75 ha respectively. The forest inventory was done in 1993, before the interventions in the same year, identifying all threes species of commercial value within $\mathrm{a} d \mathrm{bh} \geq 10 \mathrm{~cm}$ and all the others within a $\mathrm{dbh} \geq 25 \mathrm{~cm}$. The adopted procedure in the traditional harvest area was of cutting down the threes without following any proper technical criteria, and at the planned area were used the management techniques developed by IMAZON (Instituto do Homem e Meio Ambiente da Amazônia). Evaluating the impact of all the exploitation procedures upon the fitosociological attributes of density (absolute and relative), 
dominating (absolute and relative) and Covering value index (IVC) and upon the diversity of threes species in the forest observed in both treatments, compound by 167 species in the permanent protection area, 188 species in the area of planned exploitation, and 116 in the area of traditional exploitation. Where Shannon and Simpson index pointed out low or no difference within the forest diversity among the different treatments in the different years. 


\section{INTRODUÇÃ̃o}

Tomando emprestado um pressuposto identificado por Leonardo Boff citado por Krause (1996) que diz: "no imaginário dos pais fundadores da sociedade moderna, o desenvolvimento se movia dentro de dois infinitos: o infinito dos recursos naturais e o infinito do desenvolvimento rumo ao futuro", verifica-se uma premissa aceitável visto as escalares depredações observadas nos ambientes naturais atuais em comparação aos anteriores.

A atividade madereira, por ter tornado-se uma das principais fontes econômicas na região Amazônica, apresenta papel relevante nas depredações observadas nos ambientes naturais, baseadas nos empreendimentos irresponsáveis que se alastraram pela região a partir da década de 60 , que desconsideraram a importância de se instituir estratégias que minimizassem os riscos ao ecossistema, causado pelo processo de exploração predatória.

Numa avaliação histórica, revelou-se que a exploração madeireira representa um uso da floresta que sempre se apresentou como opção para as vastas áreas que não podem ser aproveitadas para a agropecuária (Fearnside, 1993; Bush, 1996; Barros \& Uhl, 1997). Por muito tempo esse tipo de intervenção foi considerada "comum", em parte pelo desconhecimento da importância das espécies aos habitats naturais e em outra pelo "pragmatismo do desespero" encorajado pela visão gananciosa dos empreendedores.

A região de Paragominas-PA, onde foi desenvolvido o estudo, teve dois principais ciclos em sua economia: da década de 60 a 80 (atividade pecuarista) e a partir de 80' (atividade madereira), ambos com grave influência na predação e fragilização do ecossistema local. 
A partir do aspecto instituído para essa região, busca-se, então, por alternativas que desviem as estratégias de impactos similares nos empreendimentos futuros, apresentando diretrizes coerentes e viáveis para minimizar o processo depredativo e alentar o desenvolvimento com foco maior às práticas conservacionista, permitindo o uso desses ambientes conforme a receita de sustentabilidade.

Essa receita pode ser dada a partir do estabelecimento de sistemas mais aperfeiçoados de administração florestal que incentivem o controle sobre o uso sustentável das áreas florestais: preservando a biodiversidade, promovendo o equilíbrio ecológico, protegendo e revertendo as tendências predominantes de desmatamento e desertificação (Schneider et al., 2000; Owubah et al., 2001) .

O principal meio para se vislumbrar essa idéia deve ser, antes de tudo, através da compreensão da diversidade local a partir de inventários florestais que, segundo Péllico \& Brena (1997), devem ser executados periodicamente, afim de que se acompanhe e avalie instrumentos como a dinâmica das mudanças e o crescimento das florestas, fundamentais para o manejo racional dos ambientes. Sendo esse acompanhamento, segundo Amaro (1993), necessário, tal a crescente conscientização por parte da sociedade científica a despeito da fragilidade e complexidade dos ecossistemas amazônicos.

A avaliação desses instrumentos também deve ser mister na visualização do impacto da atividade madereira por práticas predatórias. Entretanto, conforme Vidal et al.(1998) e Higuchi et al. (1997), estes instrumentos foram pouco avaliados na maioria dos estudos que apresentam a atividade madereira como uma prática de impacto significativo ao ecossistema. Impacto citado por Bazzaz \& Pickett (1980) como um mecanismo que exerce grande influência na sucessão pela mudança de níveis dos recursos disponíveis, e na eficiência do recrutamento das espécies vegetais.

Logo, o entendimento do papel das diferentes espécies na comunidade, bem como a sociabilidade específica, é de valiosa importância para o detalhamento da dinâmica e estrutura das formações vegetais (Rodrigues, 1988; Naeem et al., 1994 
e Muniz et al., 1994). A compreensão da diversidade das espécies e do ambiente como um todo é primaz na exploração madeireira por ser possivel, assim, dar melhor atenção aos sistemas de manejo, incorporando a diversidade de espécies arbóreas (Martini et al., 1994) e técnicas de intervenções silviculturais (Ribeiro et al., 1999)

A análise estrutural das formações vegetais, segundo Montoya Maquim(1966), é baseada por diversos autores nas características fisionômicas da vegetação e de habitat. Todavia, a técnica desenvolvida por Cain et al. (1959) , Lamprecht(1990) e Finol(1971), de análise estrutural baseada em elementos quantitativos como a abundância, dominância e freqüência, se estabeleceu para a maioria dos estudos posteriores como a melhor forma de interpretação estrutural dos ambientes florestais.

Esses elementos contribuem no entendimento de questões relacionadas a regulagem e distribuição das espécies e a importância de cada uma na comunidade (Pinto-Coelho, 2000), apesar da vegetação tropical mostrar-se de difícil análise, em função do grande número de espécies raras e poucas espécies abundantes (Korning et al., 1991; PiresO'Brien \& O'Brien, 1995; Vidal et al., 1998; Oliveira \& Mori, 1999). É possível ainda a utilização dos índices de diversidade, no auxílio desse entendimento, por apresentarem a situação em que as espécies estão eqüitativamente abundantes na área amostrada.

Existem inúmeros índices de diversidade que auxiliam na compreensão dos povoamentos, pois consistem na medida (ou estimativa) da quantidade de diferentes espécies nas áreas amostradas e em virtude de muitas vezes estar centralizado para estudos ecológicos e estabelecimento de prioridades conservacionistas(Pielou, 1994; Hellmann \& Fowler, 1999). Sendo os mais utilizados: os de Shannon-Weaver e de Simpson (Magurran, 1988).

Essa prioridade vem recebendo maior atenção e cobrança por parte da sociedade. Portanto, pretende-se nesse trabalho explanar a situação em que uma área submetida a exploração tradicional (predatória) e planejada de madeira se comportou 
em termos de fitossociologia e diversidade durante 7 anos, afim de contribuir em estudos posteriores que abordem os efeitos desse dois tipos de exploração em áreas de florestas naturais nativas.

Os dados avaliados nesse trabalho, cedidos pelo IMAZON - Instituto do Homem e Meio Ambiente da Amazônia, foram coletados em uma área de 210 ha, na Fazenda Agrosete - Paragominas/PA, submetida em 75 ha a exploração tradicional, 105 ha a exploração planejada e 30 ha como área de preservação permanente. Sendo implantado um bloco amostral de 24.5 ha (subdividido em parcelas de $25 \mathrm{~m}$ de largura e $700 m$ ou $350 m$ de comprimento) em cada uma dessas áreas que serviu de orientação para o teste das hipóteses:

\subsection{Hipótese}

- Há variações e diferenças na estrutura populacional da vegetação entre os tratamentos antes da exploração;

- Há grande variação na magnitude das alterações entre os tratamentos.

- Há melhor recomposição da cobertura na área submetida a exploração planejada que na área submetida a exploração predatória.

\subsection{Objetivos}

1 Avaliar a adaptação das espécies aos regimes de perturbações por práticas de Extração Tradicional e Extração Planejada;

2 Identificar possíveis mudanças ao longo do tempo na estrutura da vegetação, composição e diversidade das espécies nas áreas submetidas a Exploração Planejada e Tradicional; 


\section{REVISÃO DE LITERATURA}

O processo de degradação dos ambientes naturais vem preocupando uma gama cada vez maior da sociedade mundial, em função das limitações biofísicas que o planeta vem enfrentando. Sendo os olhares dessa sociedade voltados para o que resta de ambientes com recursos naturais ainda disponíveis, com atenção maior dada à Amazônia (Corrêa, 1988; Rebouças, 1997; Leonel, 1998).

A idéia de desenvolvimento para essa região longínqua do trópico americano começou a tomar forma a partir dos idos da década de 60 , com evolução preocupante a partir da segunda década posterior (Gash et al., 1996; Nobre \& Gash, 1997) , apresentando levantamentos científicos alarmantes, e até certo ponto "histéricos", sobre o devastamento da cobertura vegetal na região.

Esses levantamentos, em alguns casos, descentralizaram a atenção dos processo naturais promovidos por esse ecossistema complexo. Desconsiderando os distúrbios naturais promovidos por ciclones, tempestades, secas, inundações, deslizamentos de terras e fogo (White \& Pickett, 1985; Attiwill, 1994).

Isso talvez minimize os ataques ao "processo de mau uso do solo" como único agente no "processo de predação da vegetação", pois os distúrbios naturais promovidos pela natureza têm papel fundamental no desenvolvimento da floresta, conforme Silva (1998) e Lamprecht (1990), por eliminar algumas plantas para liberar espaço para outras crescerem.

Entretanto, esse argumento não retira o "processo de mau uso do solo" do papel de vilão no "processo de predação da vegetação", e, no que tange o processo de exploração predatório de madeira, esse agravante toma proporções maiores em vista do "pragmatismo do desespero" encorajado pela visão gananciosa dos em- 
preendedores do ramo. Com tomadas de decisões descompromissadas para com as necessidades biológicas do ecossistema.

Há mais de 300 anos explora-se as madeiras da Amazônia, segundo Barros e Uhl (1997), mas essa exploração se deteve até o começo do século às margens dos rios, talves pela falta de interesse, recursos ou tecnologia para extensão dessa atividade ao interior da floresta.

No séc. 19 os produtos mais exportados da Amazônia se restringiam ao Cacau, Castanha, Borracha, sementes e raizes. Sendo a madeira utilizada apenas como complemento nas ao mercado de exportação. Entretanto, essa situação começou a ser revertida a partir da primeira metade do séc. 20 até a década de 50 com a exportação de dormentes para a Europa. Sendo que a comercialização de dormentes acabou e deu início ao comércio de madeiras de lei em toras e em "pranchas" (Barros \& Uhl, 1997). Dando um novo impulso ao comercio de madeiras na Amazônia

Antes da déc. 70 a exploração de madeira se restringia à várzea, mas a partir da abertura de estradas, como a Belém-Brasília(PA-010), Belém-Marabá (PA-150) e a Santarém Cuiabá (PA-150), a extração de madeira de terra firme se intensificou, estabelecendo uma boa infra-estrutura onde as industrias são verticalizadas, com equipes de extração próprias na exploração de mais de 100 espécies, e se extendem ao longo da rodovia PA-010 (Veríssimo et al., 1992). Enquanto, ao longo da rodovia PA-150, na região de Tailândia o padrão de infra-estrutura das industrias é precário e de baixa intensidade exploratória (Johns et al., 1996; Veríssimo et al., 1995).

Conforme Silva (1998), a extração de madeira em tora teve um aumento na produção de $46 \%$ de 1988 a 1995, sendo extraídos ainda cerca de 29.5 milhões de metros cúbicos só em 1996. Correspondendo em cerca de 7.3 milhões de árvores (considerando o volume médio por árvore de 4 metros cúbicos) (Barreto et al.,1998).

Segundo Verissimo et al., 1992 e Barreto et al.,1998, no município de Paragominas, onde foi desenvolvido esse trabalho, a economia conheceu, até hoje, dois ciclos bastante distintos: 
- O primeiro, estendendo-se de 1960 a 1980, onde houve a ocupação de terras pelos pecuaristas, que, para permitir a criação de pastagens, derrubavam ou queimavam as florestas, sem que fosse dado à madeira qualquer aproveitamento econômico. Calcula-se, hoje, que por esse meio tenha sido destruido cerca de um quarto de toda a cobertura vegetal primitiva do município.

- De 1980 a 1990, coube aos madeireiros marcar uma presença muito forte na economia de Paragominas, através da compra dos detentores de grandes áreas florestais os direitos de exploração da madeira. Depois de submetidas à extração seletiva, com a retirada das árvores de valor comercial, essas áreas eram derrubadas pelos fazendeiros e a seguir igualmente transformadas em pastagens. Foi nesse período que Paragominas teve sua economia fortemente aquecida pelo dinheiro oriundo da extração madeireira, chegando a concentrar na cidade, em certa época, perto de duas centenas de serrarias.

A atividade madeireira é entendida ainda como uma atividade geradora de divisas e um agente causador de devastação nos ambientes florestais (Peres, 2001; Walker et al., 2000; Rock, 1996; Fujisaka et al., 1996; Samanez, 1994; Loureiro, 1990), mas tenta apresentar subsídios que conduzam ao bom andamento dessa atividade. Pois, entende-se que as condições de ambiente em cada local são definidas conforme inúmeras associações de espécies florestais, que também modificam-se e adaptam-se de acordo com as diferentes interferências promovidas pelo ser humano.

Portanto, é evidente que o entendimento dos parâmetros fitossociológicos podem contribuir, consideravelmente, para o desígnio de medidas de utilização e recuperação do ambiente vegetacional, dando aproveitamento às espécies vegetais dentro de um conceito conservacionista, atendendo as prioridades e necessidades a estas, a partir do conhecimento dos dados referentes a abundância, freqüência, dominância e Índices de Valor de Importância e Cobertura (Lorenzo et al., 1994; Felfili \& Venturoli, 2000; Janos \& Papp, 2000).

Deve-se ainda, dar maior atenção a diversidade biológica, incluindo a variedade genética dentro das populações e espécies, a variedade de espécies da flora, 
da fauna e de microorganismos, a variedade de funções ecológicas desempenhadas pelos organismos nos ecossistemas; e a variedade de comunidades, habitats e ecossistemas formados por esses organismos, buscando o entendimento sobre as associações e a viabilidade de populações que ocorrem com uma gama de genes suficientes para perpetuar organismos ou ecossistemas (Mcminn, 1991; Pires-O'Brien \& O'Brien).

A presença ou ausência de certas espécies, bem como a sua densidade nos ecossistemas, pode trazer muitas informações sobre a qualidade do ambiente. Isto ocorre porque as espécies respondem fielmente aos parâmetros ambientais que garantem a sua sobrevivência, ou seja o habitat das espécies, ou mais amplamente o hipervolume (conceito de nicho ecológico). Quando o ambiente natural é alterado, o equilíbrio ecológico se altera, fazendo com que haja um novo panorama biológico, vinculado à nova realidade. Com a redução na densidade de indivíduos e de espécies no ambiente, algumas populações resistentes ao stresse, antes com abundâncias controladas pela competição, encontram espaço e recursos disponíveis para crescer e dominar o ambiente.

Com o crescimento descontrolado de organismos resistentes e o desaparecimento de outros sensíveis, o ecossistema reduz sua diversidade, bem como sua equitabilidade, ou seja, a distribuição de indivíduos para cada espécie tornase menos homogênea. Quando um ecossistema é dominado quantitativamente por poucas espécies, ele normalmente encontra-se sob stresse (ambiental, biológico ou antrópico).

Ecologistas têm definido o problema como amplo, sugerindo aproximações para o manejo florestal geral e para florestas nacionais especificamente. Uma delas, segundo McMinn(1991), diz respeito a criação de programas de biodiversidade que dêem atenção maior às espécies ameaçadas e em fase de extinção. Bem como atenção em relação a importância da diversidade biológica para evolução e para a manutenção dos sistemas necessários a vida da biosfera (Ministério do Meio Ambiente, 2000).

Assim, é possível observar a diversidade biológica não como uma dis- 
ciplina, mas como um ponto de vista alternativo que pode ajudar a guiar a coordenar recurso naturais, pesquisas e manejo. Tomando-se o desafio de uma pesquisa primária em determinar os tipos e níveis de manejo compatíveis com a perpetuação das populações viáveis e unidades ecológicas (Mcminn, 1991).

Deve-se utilizar, portanto, ferramentas que contemplem os componentes de diversidade (riqueza, a abundância relativa das espécies, geralmente chamada de regularidade, equitabilidade ou uniformidade). E essas ferramentas são chamadas de índices de diversidade, tendo os mais conhecidos e usados: índice Shannon, de Shannon-Weaver ou Shannon-Wiener, e Simpson (Magurran, 1988; Crawley, 1997; Pitkänem, 1998; Ferreira \& Prance, 1998; Lévêque, 1999).

Os tipos e níveis de manejo compatíveis ao ambiente é dado a partir do entendimento desses componentes de diversidade, pois a presença de espécies em um ecossistema é o resultado de um equilíbrio dinâmico que ocorre a partir de inúmeros fatores, citados por Lévêque (1999) como:

1. O controle da composição e da estrutura das populações, através das características do meio, é um dos principais elementos que estruturam a distribuição e abundância da diversidade biológica, a partir das limitações ecológicas de natureza física, química ou biológica;

2. Interações biológicas, expressa na competição entre espécies: comportamento predatório, competição pelos recursos alimentares, competição pela ocupação do espaço, etc.;

3. Fenômenos históricos que expliquem a freqüência e amplitude dos processos de colonização e de dispersão que tendem a aumentar a riqueza de espécies, e por outro lado, dos fenômenos de emigração que tendem a reduzir a riqueza de especíes e riqueza específica.

Segundo Crawley (1997), os processos geradores e mantenedores de biodiversidade podem ser vistos como: a riqueza de espécies, equitabilidade (uniformi- 
dade) e abundância relativa, estrutura física das comunidades de plantas, sucessão e modelos de dinâmica espacial. Sendo que esses processos são responsáveis pelo(a):

1. Entendimento da uniformidade espacial e constante temporal das espécies, para elucidação da existência de equilíbrio na comunidade, com especial atenção: a variação temporal, a habilidade competitiva e de dispersão, a separação de nichos, a herbivoria, a perturbação da superfície do solo, aos refúgios que agem como uma fonte de propágulos que são dispersados e os índices de diversidade (riqueza de espécies);

2. Percep̧̧ão das diferenças entre comunidades para o reconhecimento das maneiras que podem influenciar no estudo de riqueza de espécies, sendo as de maior destaque: a abundância relativas de diferentes espécies, o grau de agregação de cada espécie e grau de distribuição espacial de diferentes espécies (equitabilidade (uniformidade) e abundância relativa);

3. Compreensão da estrutura tridimensional (estrutura vertical e horizontal) das diferentes comunidades de plantas (estrutura física das comunidades de plantas);

4. Conhecimento do processo pelo qual uma comunidade de planta muda em uma outra comunidade, envolvendo a imigração e extinção de espécies (sucessão);

5. Entendimento dos modelos de dinâmica espacial.

Portanto, acredita-se que somente a partir da utilização dessas ferramentas, indicadores e conhecimentos básicos sobre o ambiente poderá ser possível a viabilização de novos conceitos e diretrizes aceitáveis para o bom uso dos ecossistemas como um todo. 


\section{MATERIAL E MÉTODOS}

\subsection{Caracterização da Área de Estudo}

\subsubsection{Município de Paragominas - PA}

Conforme descrição feita por Silva (1998), a área onde desenvolveuse o estudo (Fazenda Agrossete) fica localizada no município de Paragominas, no nordeste do Estado do Pará, entre as coordenadas $2^{0} 25^{\prime}$ e $4^{0} 09^{\prime} S$ e $46^{0} 25^{\prime}$ e $48^{0} 54^{\prime} W$, a $30 \mathrm{~km}$ da sede do município.

Este município é drenado pelas bacias do rio Capim e do Gurupi, foi fundado em 23 de janeiro de 1965, a $316 \mathrm{~km}$ de Belém pela rodovia federal Belém / Brasília. Foi estabelecida nos anos 60 como uma fronteira de pecuária (600 mil cabeças), estimulada por incentivos fiscais. Possuindo ainda, desenvolvimento econômico na atividade madereira e produção de grãos (soja, milho e arroz) (Almeida \& Uhl, 1997; Schneider et al., 2000).

Segundo dados da Embrapa/CPATU (1973-1982), citados por Silva (1998), o clima é caracterizado por um período com chuvas regulares (janeiro/maio) e um período mais seco (junho/novembro), com pluviosidade média $40 \mathrm{~mm} / \mathrm{mês}$ e $1700 \mathrm{~mm} /$ ano.

Os solos da região são do grupo Latossolo Amarelo, pobres e bem profundos, com textura indo da média a muito argilosa, com relêvo plano (Radambrasil, 1974).

A floresta apresenta-se heterogênea quanto a estrutura, podendo ter quatro categorias distintas: floresta alta, floresta média, floresta baixa e clareira, com pontos de diferenciação de uma categoria para outra amparados na densidade e 
altura das árvores e abundância de cipós. Sendo a floresta alta constituída de árvores grandes que podem chegar até a $45 \mathrm{~m}$ de altura; a floresta média caracterizada como uma transição para a floresta baixa, com altura total de 10 a $20 \mathrm{~m}$; e floresta baixa, constituída de árvores com altura máxima de 10 m e um alto índice de cipós (Silva, 1997; Barreto et al., 1998).

Segundo Vidal et al. (1997), estudos preliminares sugerem que o dossel da floresta da área de estudo era composto de $18 \%$ na fase de floresta alta, $46 \%$ na fase de floresta média, $28 \%$ na fase de floresta baixa e $8 \%$ na fase de clareiras. Entretanto é visível hoje, em média, quatro clareiras por hectare (Silva, 1998), possivel situação fruto do desenvolvimento desordenado promovido durante esse anos.

\subsection{Atividades desenvolvidas e coleta de dados}

Conforme descrição feita por Silva (1998), foram dois os sistemas de exploração: Planejado e Tradicional (também chamada Predatória). O sistema de Exploração Planejada foi desenvolvido em uma área de 105 ha e o de Exploração Tradicional em uma área de 75 ha.

Em cada uma dessas áreas foram implatadas parcelas amostrais que totalizam 24.5 ha cada, sendo que a reunião dessas parcelas foi feita por agrupamento, formando um bloco estabelecido de forma aleatória. Identificou-se todas as árvores com DAP $\geq 10 \mathrm{~cm}$, codificando-as em um sistema de coordenadas $x y z$ e marcadas com placa de alumínio, com espaço reservado para anotação das medições de DAP nos anos subsequentes.

A primeira medição foi feita antes da exploração em 1993 e após a exploração em 1994, 1995, 1996, 1998 e 2000.

\subsubsection{Sistema de Exploração Planejada}

Foi desenvolvido pelo Instituto do Homem e do Meio Ambiente da Amazônia (IMAZON) e compreende três etapas: 
1 Atividades antes da Exploração:

- 2 anos: Delimitação do talhão com e abertura de trilhas para realização de censo dos indivíduos com DAP $\geq 25 \mathrm{~cm}$;

- 1 a 2 anos: Corte de cipós $\geq 2 \mathrm{~cm}$ de diâmetro, presentes nas árvores a serem derrubadas;

- 3 meses: Delimitação das estradas principais e pátios de estocagem. Seleção das árvores a serem derrubadas.

2 Atividades durante a Exploração:

- Poucos dias antes uma equipe de planejamento entra na floresta e faz orientação da colheita;

- Orientação de pequenas trilhas marcadas com balizas e fitas plásticas coloridas;

- Confecção de mapa para simples conferência pela equipe de derrubada e de arraste;

- Orientações são distribuídas na abertura de estradas principais para caminhões, nos pátios de estocagem, nos ramais de arraste e na direção ideal de queda das árvores.

\section{Atividades após a Exploração}

- Tratamentos silviculturais e monitoramento através de medições anuais de crescimento. Entretanto, somente o monitoramento tem sido feito.

\subsubsection{Sistema de Exploração Tradicional}

É o mais utilizado na região de Paragominas e em grande parte da Amazônia e segue as seguintes etapas:

- Definição da área de exploração, sem um conhecimento preliminar da localização das árvores de interesse para o corte; 
- Localização e corte das árvores de interesse por uma equipe de motosseristas;

- Construção de estradas de arraste;

- Construção de pátio de estocagem para um aglomerado de toras cortadas, montado em local de boa topografia e de poucas árvores grandes que possam dificultar a abertura da área;

- Arraste das toras derrubadas, por trator de esteira sem guincho, dos ramais provisórios até as estradas de arraste e por conseguinte até os pátios de estocagem, de onde são levadas para as serrarias.

\subsection{Descrição do Sistema de Amostragem}

Normalmente, o inventário florestal é o primeiro passo para lançar a base das pesquisas referentes a recursos naturais e também para a tomada de qualquer decisão relacionada ao uso da terra (Higuchi et al., 1982; Pélico \& Brena, 1997), com implantação de áreas amostrais que atendam aos objetivos de máxima informação com máxima precisão e um custo mínimo afim de se obter boas medidas e estimativas.

Routledge (1998), entretanto, afirma que medidas e estimativas nunca são perfeitas e que o potencial de erro está sempre presente, especialmente em estudos de campo. Apesar disso, nesse trabalho, o sistema de amostragem adotado na coleta de dados foi em dois estágios, ou seja, as unidades primárias (blocos) foram tomadas aleatoriamente e as secundárias de forma sistemática (sub-blocos) (Husch et al., 1982 e Péllico \& Brena, 1997).

Nas unidades primárias (blocos) implantadas nas áreas submetidas a exploração houve subdivisão destes em 14 unidades secundárias (sub-blocos ou parcelas) de $25 \mathrm{~m} \times 700 \mathrm{~m}$. Enquanto que no bloco da área de preservação essa subdivisão foi de 28 unidades secundárias (sub-blocos), ou parcelas, de $25 \mathrm{~m}$ X $350 \mathrm{~m}$.

O sentido de medição no bloco da área de exploração tradicional e no bloco da área de preservação foi contrário ao "sentido crescente" do eixo da coorde- 


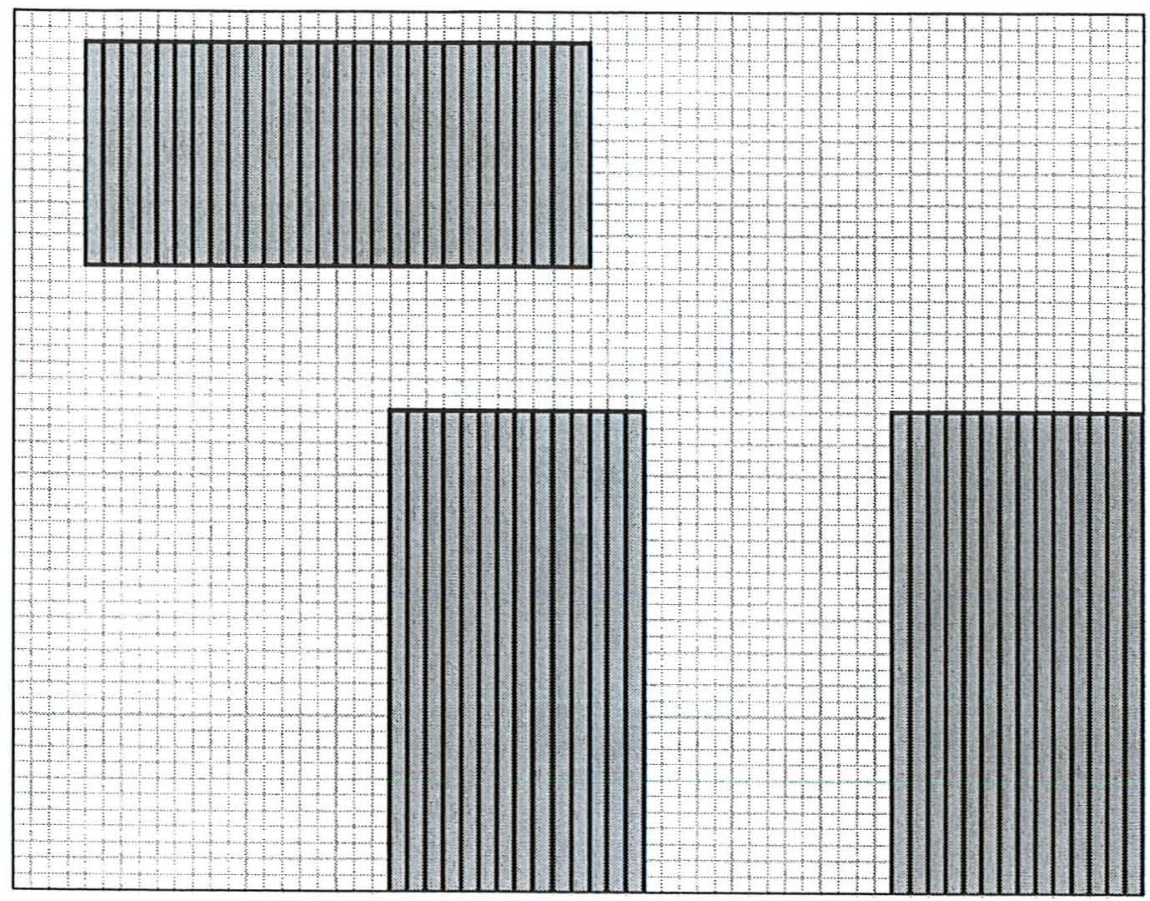

Figura 1 - Distribuição das parcelas amostrais nos blocos permanentes. Sendo: o bloco superior relativo à Área de Proteção Permanente, o bloco a baixo e à esquerda à Área submetida a Exploração Tradicional, e o bloco a baixo e à direita relativo a Área submetida a Exploração Planejada

nada x. Entretanto, no bloco da área de exploração tradicional adotou-se o "sentido crescente" da coordenada acima citada.

A tomada dessa decisão, bem como implantação e medição, foi feita pela equipe do IMAZON. Sendo que o critério no sentido de medição não teria grande importância se não houvesse o interesse em plotar os indivíduos medidos em um mapa de distribuição destes nas áreas de intervenção e na área de Preservação Permanente.

As coordenadas foram assim relacionadas:

$x=$ largura $; y=$ comprimento $z=$ parcelas

- Área de preservação permanente: 
$x=0$ a $25 \mathrm{~m} y=0$ a $350 \mathrm{~m} z=1$ a 28 faixas

- Área submetida à Exploração manejada: $x=0$ a $25 \mathrm{~m} y=0$ a $700 \mathrm{~m} z=1$ a 14 faixas

- Área submetida à Exploração tradicional: $x=0$ a $25 \mathrm{~m} y=0$ a $700 \mathrm{~m} z=1$ a $14 \mathrm{~m}$ faixas

Nos blocos em que o sentido de medição foi contrário ao "sentido crescente" do eixo $\mathrm{x}$ foi necessário uma adequação na planilha de dados para um vislumbre correto na distribuição dos indivíduos no eixo de coordenadas xyz. Ou seja, foi feita a inversão na distribuição das percelas com o cuidado de não alterar a posição dos indivíduos nos respectivos sub-blocos ou parcelas.

A preocupação em relação a posição dos indivíduos no eixo de coordenadas $x y z$ foi apenas um detalhe. Sendo a análise da composição florística, através da distribuição dos indivíduos, espécies e famílias ocorrentes nas áreas, mister nesse trabalho.

\subsection{Parâmetros Fitossociológicos}

Foram obtidos os parâmetros fitossociológicos para todas as espécies com DAP $\geq 10 \mathrm{~cm}$, considerando-se a estrutura horizontal do povoamento, representada por parâmetros que caracterizam a ocupação do solo pela vegetação no sentido horizontal da floresta. Sendo as medidas mais comuns incluidas na estimativa dessa estrutura: Densidade absoluta (DA) e relativa (DAR), Dominância Absoluta (Do) e Relativa (DoR), e o índice de Valor de Cobertura (IVC) (Mueller-Dombois \& Ellemberg, 1974; Muniz et al.,1994; Ribeiro et al., 1999; Barros et al., 2000; Janos \& Papp, $2000)$.

- Densidade Absoluta e Relativa 


$$
\begin{aligned}
& D A_{i}=\frac{N_{i}}{A} \\
& D R_{i}=\frac{D A}{\sum_{i=1}^{n} D A} * 100
\end{aligned}
$$

Onde:

$D A_{i}=$ Densidade absoluta para $\mathrm{i}^{\text {ésima }}$ espécie $\left(\mathrm{n}^{\mathrm{o}}\right.$ ind $\left.h \mathrm{a}^{-1}\right)$

$D R=$ Densidade relativa para iésima espécie (\%)

$N_{i}=\mathrm{N}^{\circ}$ total de ind. amostrados para iésima espécie

$n=$ Total de espécies encontradas

$A=$ Área amostrada $(h a)$

- Dominância Absoluta e Relativa

$$
\begin{aligned}
D O A_{i} & =A B_{i} \\
D O R_{i} & =\frac{D O A_{i}}{\sum_{i=1}^{n} D O A_{i}} * 100
\end{aligned}
$$

$D O A_{i}=$ Dominância absoluta para iésima espécie $\left(m^{2} h a^{-1}\right)$

$D O R=$ Dominância relativa para $i^{\text {ésima }}$ espécie (\%)

$A B-i=$ Área Basal para $i^{\text {ésima }}$ espécie $\left(m^{2} h a^{-1}\right)$

$n=$ Total de espécies encontradas

$A=$ Área amostrada $(h a)$

- Indice de Valor de Cobertura

$$
I V C=D R+D O R
$$

$I V C=$ Índice de Valor de Cobertura (\%)

$D R=$ Densidade relativa para $i^{\text {ésima }}$ espécie $(\%)$

$D O R=$ Dominância relativa para iésima espécie $(\%)$ 


\section{5 Índices de Diversidade}

O conceito de diversidade de espécies é baseado no pressuposto de que as espécies interagem entre si e com o meio, e que essas interações se expressam através do número de espécies presentes e suas abundâncias relativas. Oferecendo um detalhamento que relaciona a densidade de espécies a riqueza e a abundância relativa a uniformidade ou equitabilidade, no grau de sua dominância ou falta. Sendo os índice de Shannon, de Shannon-Weaver ou Shannon-Wiener, e de Simpson os contempladores desses componentes.

O Índice de Shannon, apesar de ser um dos indicadores de diversidade mais usados, exatamente por combinar a riqueza e a uniformidade num único valor, pode apresentar desvios. Isso é especialmente notável quando se monitora a diversidade numa comunidade ou população. Nesses casos é posível que aconteçam alguns problemas: qualquer mudança num componente pode contra-equilibrar-se pelo outro, e assim, o índice tende a permanecer constante, quando de fato, ambos os parâmetros tem sido mudados; ou, o índice pode mostrar uma tendência de decréscimo, quando houver aumento de riqueza.

Esses desvios tem feito com que a literatura aponte somente a riqueza, representada pelo número de espécies, ou pela razão espécie/área, como indicadores de diversidade. Esse procedimento não pode ser aconselhável, porque tais indicadores não descobrem alterações na diversidade antes de pelo menos uma espécie desaparecer.

\subsection{1 Índice de Shannon}

Esse índice permite que o grau de heterogeneidade das áreas seja conhecido, baseando-se na abundância proporcional de todas as espécies da comunidade (Shugart, 1978). É importante não só para o número de espécies da área, mas também para densidade populacional (Pires-O'Brien \& O'Brian, 1995). 


$$
H^{\prime}=-\sum_{i=1}^{S} p_{i} \log p_{i}
$$

Onde:

$S=$ Número total de espécies;

$p_{i}=$ Proporção da amostra total que pertence a iésima espécie.

$$
p_{i}=\frac{n_{i}}{N}
$$

Onde:

$n_{i}=$ Número de indivíduos da $\mathrm{i}^{\text {ésima }}$ espécie;

$N=$ Número total de indivíduos na amostra.

\subsection{2 Índice de Simpson}

Esse índice permite avaliar a influência do registro seletivo na diversidade de espécies (Gaines et al., 1999), bem como dá a probabilidade de dois indivíduos quaisquer, retirados aleatoriamente de uma comunidade pertencerem a diferentes espécies. É uma medida principalmente de dominância e dá um peso maior às espécies comuns, ao contrário de Shannon (Felfili \& Venturoli, 2000).

$$
D=1-\sum_{i=1}^{n} p_{i}^{2}
$$

Onde:

$n=$ Total de espécies encontradas;

$p_{i}=$ Proporção da amostra total que pertence a $i^{\text {th }}$ espécie.

$\grave{A}$ medida que $D$ aumenta, decresce a diversidade. $O$ índice de Simpson's é geralmente expresso como i - D ou 1 / D. Este índice dá mais peso a abundância das espécies na amostragem sendo menos sensível à riqueza.

\subsection{Monitoramento dos Tratamentos}

Nos anos de 1994, 1995, 1996, 1998 e 2000 uma equipe de campo esteve no local onde foram medidos os indivíduos em 1993 (antes da intervenção de 
extração) e refez esse procedimento, anotando na prancheta de campo, e na placa afixada na árvore, os dados refentes aquele período.

Foram tomadas outras medidas que não estão sendo avaliadas nesse trabalho, tais como: Altura estimada, Árvores mortas em decorrência de atividades naturais, Número de lianas presentes, etc. 


\section{RESUltados E DISCUSSÃO}

\subsection{Distribuição dos indivíduos nos tratamentos}

O Mapa de Distribuição dos indivíduos, em todos tratamentos, apresentado na Figura 2, mostra o arranjo da distribuição destes nos respectivos intervalos diamétricos. O intervalo diamétrico de maior predominância de indivíduos em toda a área, nos três tratamentos, fica entre $25 \mathrm{~cm}$ e $50 \mathrm{~cm}$ (5402 ind.), seguido do intervalo entre $10 \mathrm{~cm}$ e $25 \mathrm{~cm}$ ( 4582 ind.), $50 \mathrm{~cm}$ e $75 \mathrm{~cm}$ (750 ind.), $75 \mathrm{~cm}$ e $100 \mathrm{~cm}$ (181 ind.), e 67 indivíduos com dap $\geq 100 \mathrm{~cm}$.

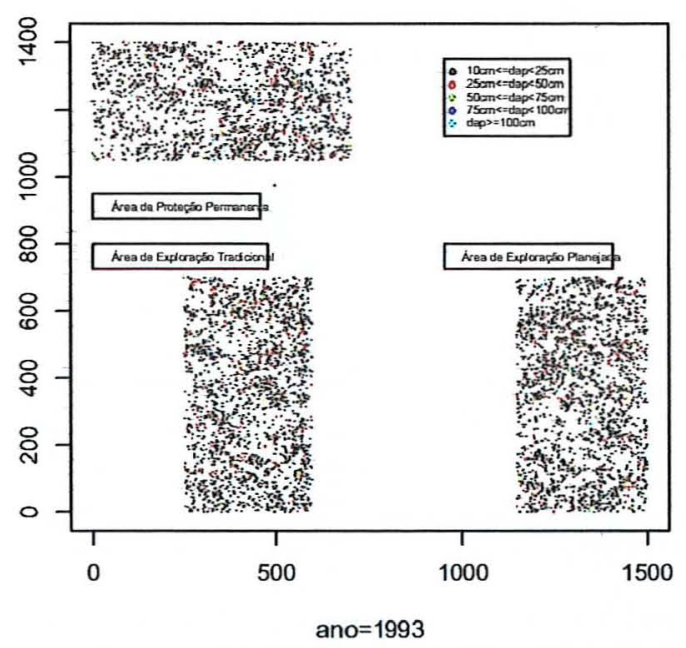

Figura 2 - Mapa de Distribuição das espécies, em todos tratamentos, com seus respectivos intervalos diamétricos. 
Na área de exploração tradicional, conforme Tabela 1, houve uma redução de 295 indivíduos na classe diamétrica de $25 \mathrm{~cm} \leq$ dap $<50 \mathrm{~cm}$ após a exploração, com aumento gradativo dessa redução ao longo dos anos e com perda média anual de 20 indivíduos. Na classe diamétrica de $10 \mathrm{~cm} \leq$ dap $<25 \mathrm{~cm}$ houve redução de 291 indivíduos logo após o processo de extração e uma redução média de 63 indivíduos ao longo dos anos. Na classe diamétrica de $50 \mathrm{~cm} \leq$ dap $<75 \mathrm{~cm}$ a redução foi de 63 indivíduos no ano posterior ao processo, com inclusão gradativa de novos indivíduos nessa classe a partir de 1995. Na classe diamétrica de $75 \mathrm{~cm} \leq$ dap $<100 \mathrm{~cm}$ houve redução de 45 indivíduos após esse processo de extração, sem alteração significativa no número de indivíduos estabelecidos após esse processo. Houve também redução de 13 indivíduos na classe diamétrica de dap $\geq 100 \mathrm{~cm}$ logo após o processo de extração, sem alteração significativa no número de indivíduos estabelecidos nos anos posteriores.

Tabela 1. Número de ind no tratamento Área de Exploração Tradicional pelos diferentes anos e classes diamétricas

\begin{tabular}{ccccccc}
\hline Classe & 1993 & 1994 & 1995 & 1996 & 1998 & 2000 \\
\hline $10 \mathrm{~cm} \leq$ dap $<25 \mathrm{~cm}$ & 1481 & 1190 & 1116 & 1054 & 964 & 874 \\
$25 \mathrm{~cm} \leq$ dap $<50 \mathrm{~cm}$ & 1870 & 1575 & 1573 & 1545 & 1518 & 1476 \\
$50 \mathrm{~cm} \leq$ dap $<75 \mathrm{~cm}$ & 256 & 193 & 202 & 213 & 220 & 223 \\
$75 \mathrm{~cm} \leq$ dap $<100 \mathrm{~cm}$ & 68 & 23 & 23 & 23 & 23 & 22 \\
dap $\geq 100 \mathrm{~cm}$ & 20 & 7 & 7 & 7 & 7 & 7 \\
\hline
\end{tabular}

$\mathrm{Na}$ área de exploração planejada, conforme Tabela 2 , houve uma redução de 252 indivíduos na classe diamétrica de $10 \mathrm{~cm} \leq$ dap $<25 \mathrm{~cm}$ após a exploração, havendo redução gradativa no número de indivíduos para essa classe ao longo dos anos, com exclusão média anual de 97 indivíduos. $\mathrm{Na}$ classe diamétrica de $25 \mathrm{~cm}$ $\leq$ dap $<50 \mathrm{~cm}$ houve redução de 78 indivíduos logo após o processo de extração e uma redução média anual ao longo dos anos de 23 indivíduos. Na classe diamétrica 
de $50 \mathrm{~cm} \leq$ dap $<75 \mathrm{~cm}$ a redução foi de 31 indivíduos no ano posterior ao processo, com inclusão média de 09 indivíduos ao longo dos anos posteriores a esse processo. $\mathrm{Na}$ classe diamétrica de $75 \mathrm{~cm} \leq$ dap $<100 \mathrm{~cm}$ houve redução de 36 indivíduos após esse processo de extração, sem alteração significativa no número de indivíduos estabelecidos após esse processo. Houve também redução na classe diamétrica de dap $\geq$ $100 \mathrm{~cm}$ de 14 indivíduos logo após o processo de extração, sem alteração significativa no número de indivíduos estabelecidos nos anos posteriores.

Tabela 2. Número de ind no tratamento Área de Exploração Planejada pelos diferentes anos e classes diamétricas

\begin{tabular}{ccccccc}
\hline Classe & 1993 & 1994 & 1995 & 1996 & 1998 & 2000 \\
\hline $10 \mathrm{~cm} \leq$ dap $<25 \mathrm{~cm}$ & 1932 & 1680 & 1563 & 1462 & 1333 & 1196 \\
$25 \mathrm{~cm} \leq$ dap $<50 \mathrm{~cm}$ & 1888 & 1810 & 1849 & 1872 & 1899 & 1927 \\
$50 \mathrm{~cm} \leq$ dap $<75 \mathrm{~cm}$ & 247 & 216 & 227 & 237 & 251 & 259 \\
$75 \mathrm{~cm} \leq$ dap $<100 \mathrm{~cm}$ & 60 & 24 & 25 & 24 & 26 & 31 \\
dap $\geq 100 \mathrm{~cm}$ & 25 & 11 & 11 & 11 & 11 & 11 \\
\hline
\end{tabular}

$\mathrm{Na}$ área de proteção permanente, conforme Tabela 3 , houve uma redução de 38 indivíduos na classe diamétrica de $10 \mathrm{~cm} \leq$ dap $<25 \mathrm{~cm}$ após a exploração, havendo redução gradativa no número de indivíduos para essa classe ao longo dos anos, com exclusão média anual de 52 indivíduos. Na classe diamétrica de $25 \mathrm{~cm}$ $\leq$ dap $<50 \mathrm{~cm}$ houve redução de 27 indivíduos logo após o processo de extração e uma redução média anual ao longo dos anos de 27 indivíduos. Na classe diamétrica de $50 \mathrm{~cm} \leq$ dap $<75 \mathrm{~cm}$ houve inclusão de 08 indivíduos no ano posterior ao processo, sem alteração significativa no número de indivíduos estabelecidos após o processo de extração ocorrido nos outros tratamentos. Na classe diamétrica de $75 \mathrm{~cm} \leq$ dap $<$ $100 \mathrm{~cm}$ houve inclusão média de 2 indivíduos ao longos anos. Na classe diamétrica de dap $\geq 100 \mathrm{~cm}$ não houve alteração significativa no número de indivíduos estabelecidos ao longo dos anos. 
Tabela 3. Número de ind no tratamento Área de Proteção Permanente pelos diferentes anos e classes diamétricas

\begin{tabular}{ccccccc}
\hline Classe & 1993 & 1994 & 1995 & 1996 & 1998 & 2000 \\
\hline $10 \mathrm{~cm} \leq$ dap $<25 \mathrm{~cm}$ & 1169 & 1131 & 1080 & 1019 & 939 & 870 \\
$25 \mathrm{~cm} \leq$ dap $<50 \mathrm{~cm}$ & 1644 & 1617 & 1614 & 1571 & 1529 & 1484 \\
$50 \mathrm{~cm} \leq$ dap $<75 \mathrm{~cm}$ & 247 & 255 & 253 & 254 & 262 & 258 \\
$75 \mathrm{~cm} \leq$ dap $<100 \mathrm{~cm}$ & 53 & 55 & 58 & 62 & 63 & 64 \\
dap $\geq 100 \mathrm{~cm}$ & 22 & 22 & 23 & 23 & 23 & 25 \\
\hline
\end{tabular}

Ao longo dos anos houve uma grande redução no número de indivíduos da classe $10 \mathrm{~cm} \leq$ dap $<25 \mathrm{~cm}$, em todos os tratamentos:

- Possivelmente por essa classe ser formada somente por espécies de valor madeireiro e promover perdas estimuladas pelo processo de extração; ou

- em virtude do recrutamento dos indivíduos dessa classe para a classe diamétrica de $25 \mathrm{~cm} \leq$ dap $<50 \mathrm{~cm}$.

Esse resultado leva a crer que, além da perda de indivíduos pelo processo exploratório, pode ter havido influência da luz, a partir da abertura de dossel, em função da intervenção, que consequentemente influenciou no incremento basal de algumas espécies, promovendo o recrutamento destas ao intervalo de distribuição posterior. Num processo contínuo de recrutamento ao longo do tempo.

A redução no número de indivíduos na área de exploração tradicional foi maior na classe de $10 \mathrm{~cm} \leq$ dap $<25 \mathrm{~cm}$ que nas demais classes e tratamentos. Entretanto, a classe diamétrica que teve maior redução média ao longo dos anos foi a de $10 \mathrm{~cm} \leq$ dap $<25 \mathrm{~cm}$ na área de exploração planejada; provavelmente, pelo processo de recrutamento da classe diamétrica posterior ou por sua exclusão pelo processo de competição natural.

Não foi verificada incidência de um grande número do indivíduos na classe de $50 \mathrm{~cm} \leq$ dap $<75 \mathrm{~cm}$. Possivelmente em função dos desgastes ambientais 
promovidos por outros organismos, intervenções humanas e acidentes naturais. Entretanto, os números apresentados apontaram mais de $100 \%$ de perda na área de Exploração Tradicional em relação a área de Exploração Planejada. E, apesar das perdas, quando comparada essa classe às demais, percebe-se um aumento no recrutamento de indivíduos em todos os tratamentos. Possivelmente em função da abertura do dossel que contribui no incremento basal dos indivíduos.

\subsection{Parâmetros Fitossociológicos}

As taxas de desenvolvimento das características estruturais de bosque, tais como: densidade, dominância e altura de dossel servem para determinar as características de produtividade da área.

\subsubsection{Densidade}

A estimação desse parâmetro é a atividade mais freqüente empreendida pelos ecologista, e por ser usualmente definida como o número de indivíduos por unidade de área está diretamente relacionada às condições ecológicas do ambiente (Janos \& Papp, 2000).

Verificou-se que a estimativa desse parâmetro para o Tratamento Exploração Planejada foi a mais alta dentre os outros tratamentos nos diferentes anos. A maior redução ocorreu no tratamento exploração tradicional logo após a intervenção exploratória e a menor redução ocorreu na área de proteç ao permamente.

Tabela 4. Densidade absoluta nos diferentes tratamentos pelos diferentes anos

\begin{tabular}{lllllll}
\hline Tratamento & 1993 & 1994 & 1995 & 1996 & 1998 & 2000 \\
\hline Área de Exploração Tradicional & 150,816 & 122 & 119,224 & 116 & 111,510 & 106,204 \\
Área de Exploração Planejada & 169,469 & 152,693 & 150 & 147,183 & 143,673 & 139,755 \\
Área de Proteção Permanente & 127,959 & 125,714 & 123,591 & 119,551 & 114,938 & 110,244 \\
\hline
\end{tabular}


As Figuras 3, 4 e 5 auxiliam na compreensão dessa redução ao relacionar-se o dap dos indivíduos nos diferentes anos. Percebe-se que o comportamento destes em relação a esse parâmetro, nas áreas de exploração, foi de redução entre o ano de 1993 e 1994, onde a distribuição dos pontos inclina-se para a direita da reta. Isso provavelmente deu-se a partir das espécies com dap $\geq 45 \mathrm{~cm}$, na área de exploração tradicional, e as espécies com $45 \mathrm{~cm} \leq d a p \geq 55 \mathrm{~cm}$ na área de exploração planejada.

O comportamento da reta das Figuras 3, 4 e 5 é alterado nos anos posteriores, possivelmente devido o estado sucessional requerente na área. Isso é percebível pela reaproximação dos pontos em relaç ao a reta com suavização da inclinação desses pontos. Issso confirma a hipótese de reestrutução da vegetação em área submetida á Exploração desde que sejam aplicadas técnicas apropriadas de corte e seleção de espécies.

O comportamento das espécies na Área de Exploração Tradicional, em relação a densidade, apresentado na Figura 3 , deixa clara a redução ocorrida entre o ano de 1993 e 1994. Isso provavelmente deu-se a partir das espécies com $45 \mathrm{~cm} \leq$ dap $\geq 55 \mathrm{~cm}$, por essa ser a classe diamétrica mais requerida pelo mercado medeireiro de toras. E, possivelmente, o IMAZON, responsável pela aplicação desse trabalho, procurou aproximar-se ao máximo da realidade na região.

Observa-se que a distribuição dos pontos na Área de Exploração Tradicional inclina-se muito mais para a direita entre 1993 e 1994, retomando mais lentamente a recomposição ao longo dos anos quando comparada a distribuição dos pontos da Área de Exploração Planejada. Isso provavelmente deva ter ocorrido devido o descuido normalmente aplicado pelos empreendedores de práticas tradicionais de exploração em relação a fragilidade dos ambientes florestais.

A Figura 5 serve para fortalecer o entendimento dos gráficos anteriores, por apresentar o comportamento na distribuição do dap na área que não sofreu perturbação, e que, pela lógica, deve apresentar uma linearidade. E essa linearidade 

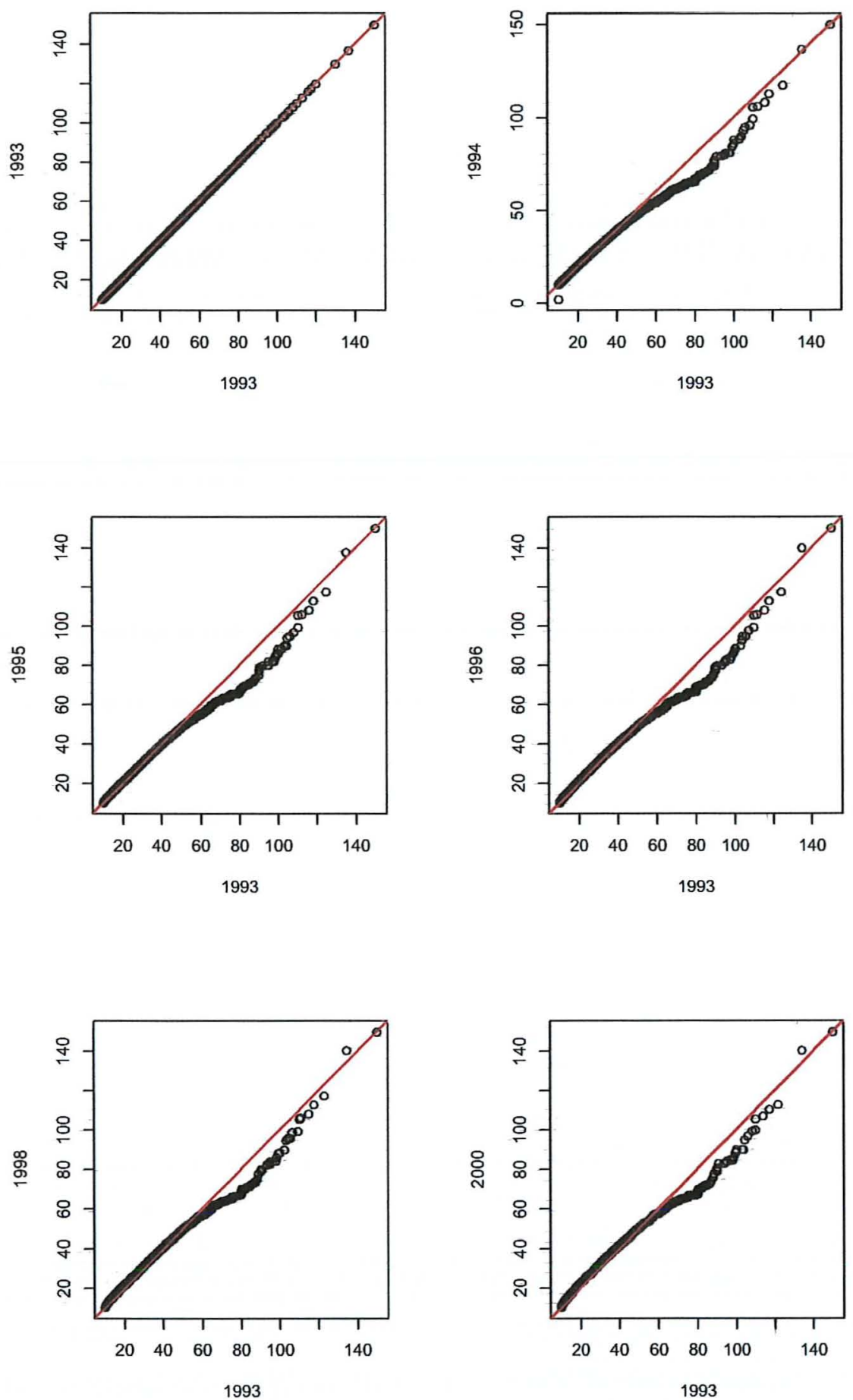

Figura 3 - Gráfico Quantil-Quantil para o diâmetro das árvores cntre o ano de 1993 c os anos $(1994,1995,1996,1998,2000)$ posteriores ao processo de extração na Área de Exploração Tradicional 

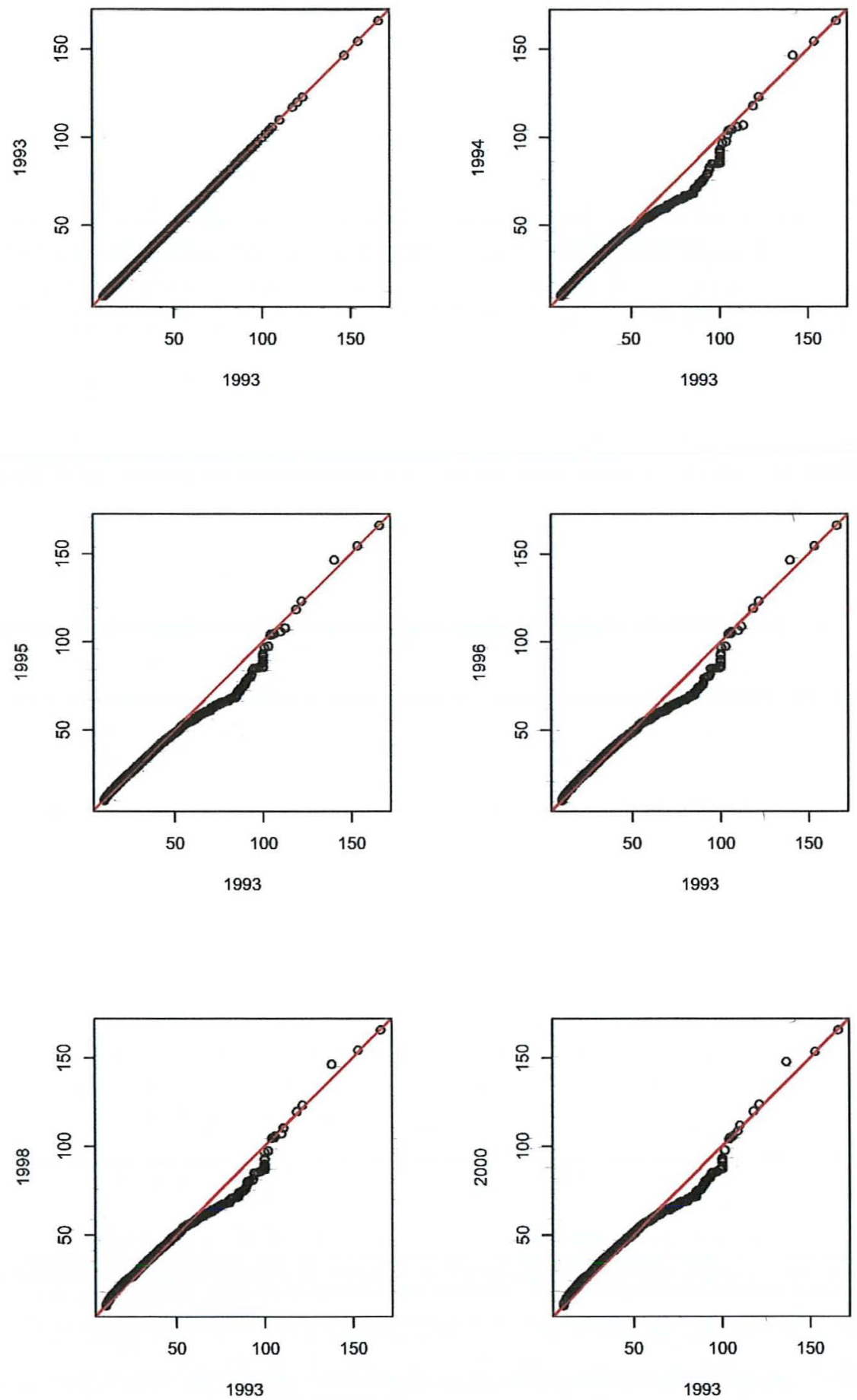

Figura 4 - Gráfico Quantil-Quantil para o diâmetro das árvores no ano de 1993 e os anos $(1994,1995,1996,1998,2000)$ posteriores ao processo de extração na Área de Exploração Planejada 

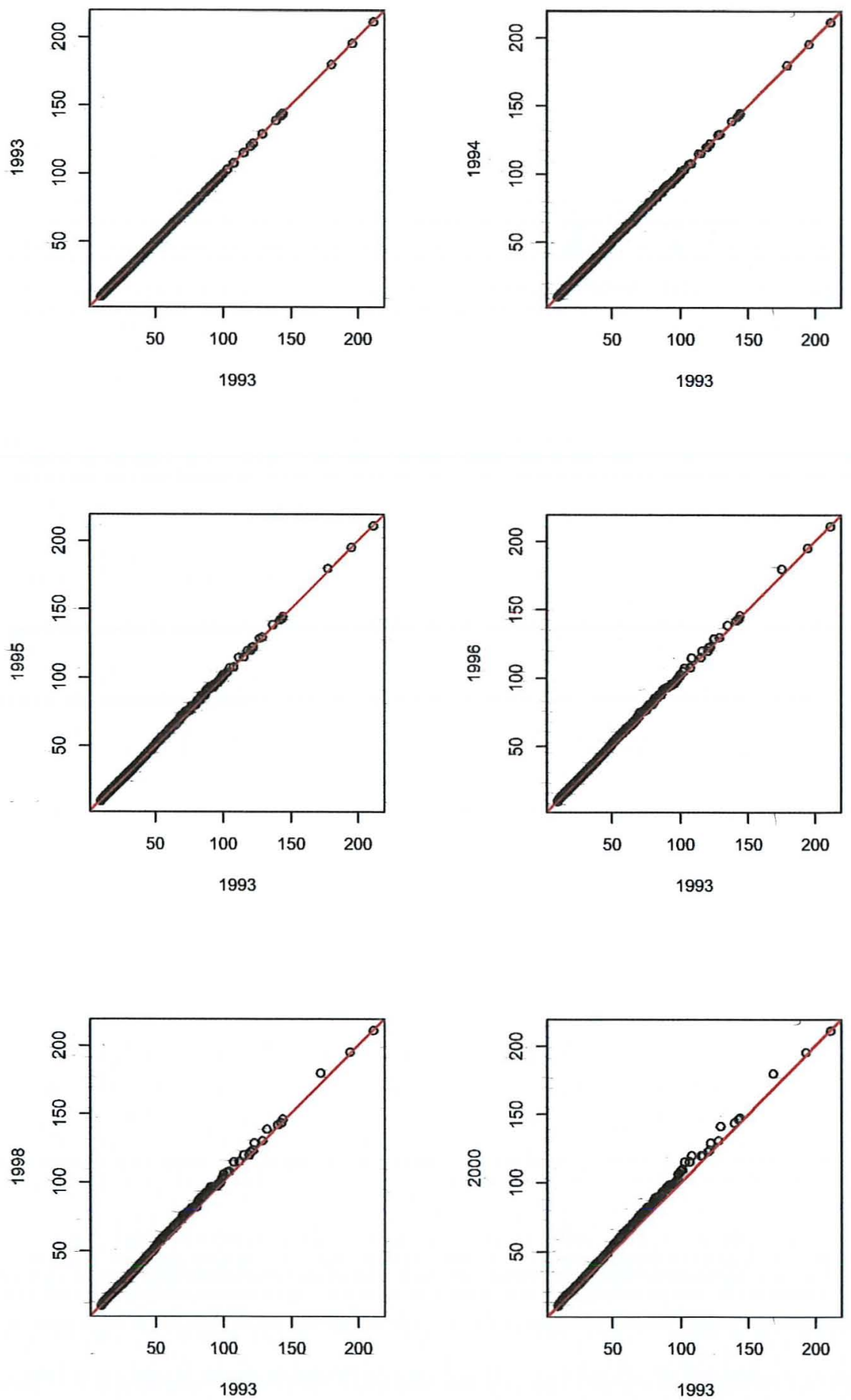

Figura 5 - Gráfico Quantil-Quantil para o diâmetro das árvores no ano de 1993 e os anos $(1994,1995,1996,1998,2000)$ posteriores ao processo de extração na Área de Proteção Permanente 
na distribuição dos pontos sobre a reta indica pouca ou nenhuma alteração de 1993 a 1994, mas que nos anos seguintes percebe-se uma discreta tendência na distribuição desses pontos mais para esquerda da reta, sugerindo um crescimento dessa vegetaç ao ao ano de 1995 em relação a 1994. Crescimento que se evidencia-se mais ainda quando comparados os anos de 1993 e 2000.

\subsubsection{Dominância}

Conforme a Figura 6, que apresenta a curva de Whittaker para o tratamento Exploração Planejada, os valores do parâmetro dominância nos diferentes anos

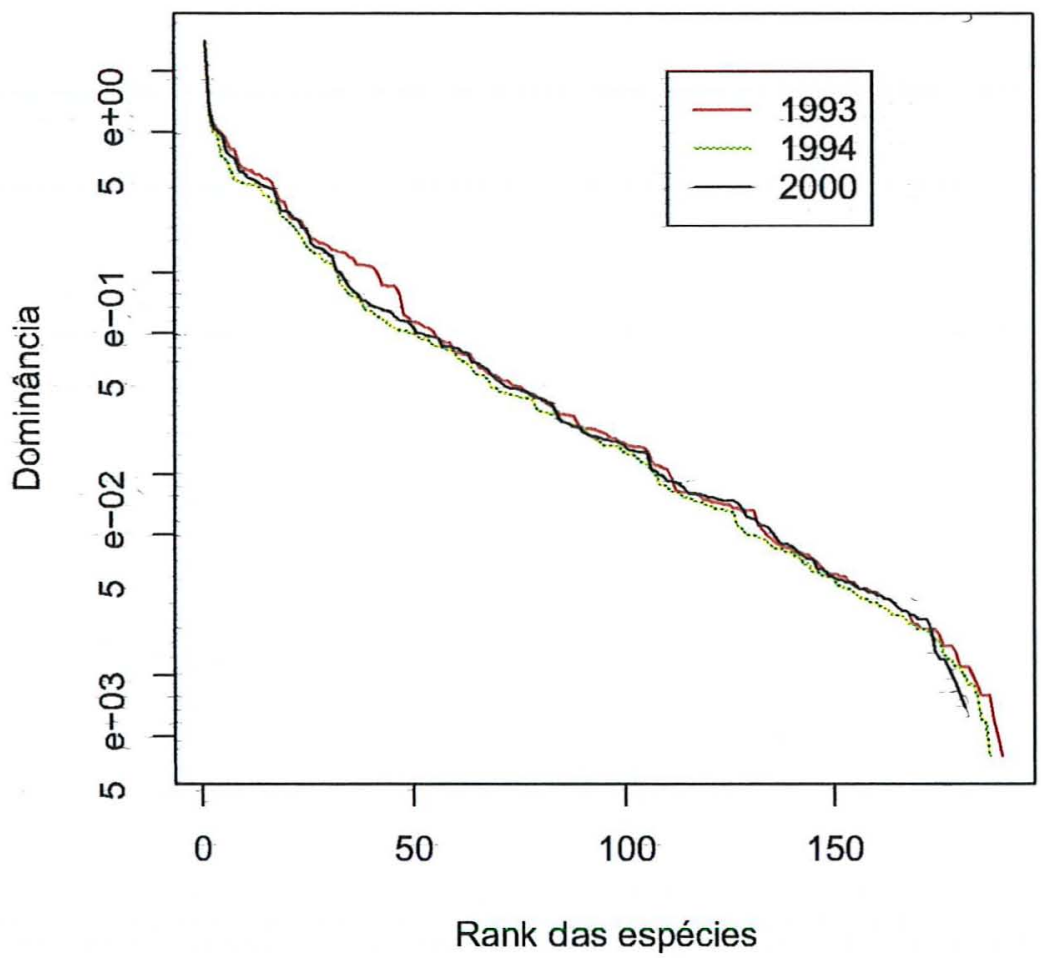

Figłra 6- Gurva de Whittaker para DOA na Área de Exploração-Planejada 


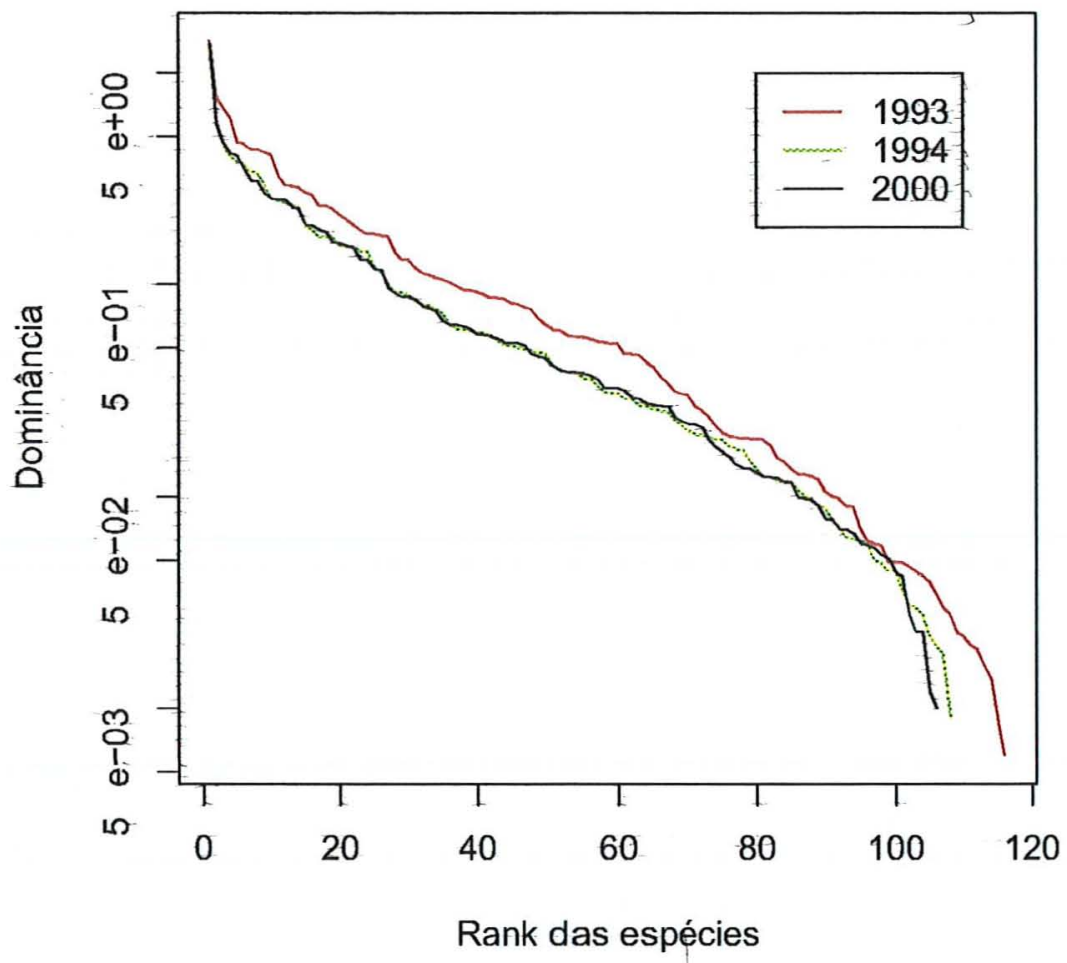

Figura 7 - Curva de Whittaker para ĐӨA na Área de Exploração Tradicional

não se alterou significantemente, ou seja, quando comparadas as linhas do rank de espécies pela dominância da vegetação no ano que antecede ao processo exploratório e os anos de 1994 e 2000 verifica-se pouca alteração entre ambas. As curvas nos diferentes anos têm comportamento semelhante para a maior parte das espécies. Entretanto, em 2000 percebe-se um aumento na dominância mínima e máxima, com redução no número de indivíduos com essas dominâncias.

É perceb́vel que ern 1993 (linkr vermelha) as espécies da região próxima a quinquagézima posição tinham proximidade à máxima dominância, mas em 1994 (linha verde) as espécies dessa posição tiveram o valor desse atributo reduzido. Sendo que a avaliação desse parâmetro para o ano 2000 (linha preta) toma 


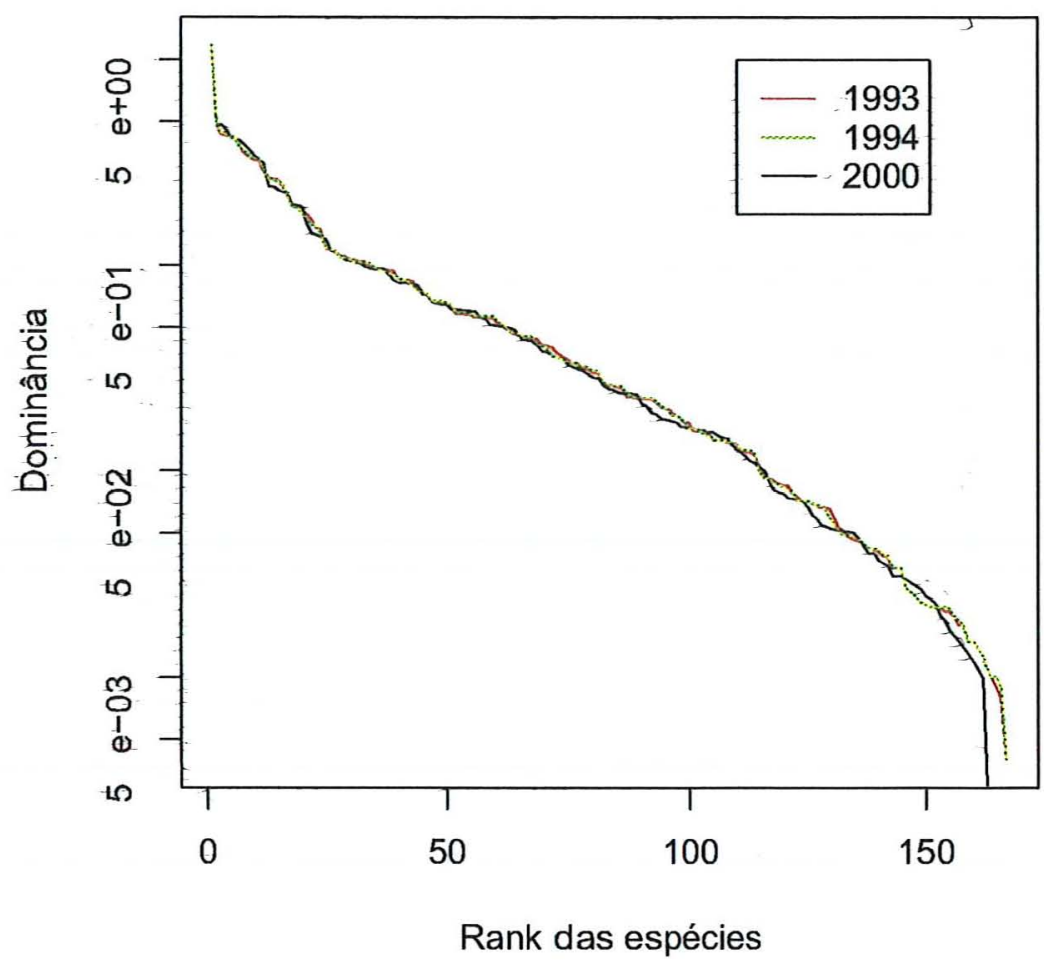

Figura 8 - Curva de Whittaker para DOA na Área de Proteção Permanente outra esfera ao perceber-se a ocorrência de uma reaproximação dos valores obtidos em 1993.

Tabela 5. Dominância absoluta nos diferentes tratamentos pelos diferentes anos

\begin{tabular}{lllllll}
\hline Tratamento & 1993 & 1994 & 1995 & 1996 & 1998 & 2000 \\
\hline Área de Exploraçã Tradieional & 334,937 & 247,806 & 251,179 & 251,360 & 250,715 & 247,433 \\
Área de Exploração Planejada & 340,605 & 288,535 & 295,769 & 300,373 & 308,492 & 314,865 \\
Área de Proteção Permanente & 395,830 & 306,562 & 308,172 & 307,758 & 308,206 & 305,811 \\
\hline
\end{tabular}


No tratamento Exploração Tradicional (Figura 7), houve redução significante na dominância em toda a extensão da curva de Whittaker, ou seja, todo o rank das espécies em 1994 sofreu alteração em toda sua extensão quando comparado ao ano anterior. Essa curva não apresentou aproximação satisfatória à 1993 em 2000, e se iguala a de 1994. Isso nos faz acreditar numa recomposição lenta das espécies desse tratamento.

Um melhor entendimento do comportamento das espécies em relação a esse parâmetro pode ser extraído da Figura 8 que apresenta o rank da dominância das espécies no tratamento Área de Proteção Permanente. Onde fica clara a não alteração brusca desse parâmetro entre o ano de 1993 e os anos seguintes. É percebível somente pequena alteração nas espécies das extremidades do rank, ou seja, as maiores e as menores espécies do rank têm reduzido sua dominância. Ocorrência possível em função da seleção natural e competição entre as mesmas.

A curva de Whittaker (Figura 7 e 8 ) para os valores obtidos de dominância no tratamento Área de Exploração Tadicional e Área de Proteção Permanente evidencia uma diferença altamente significativa entre ambas. Bem como, evidencia um comportamento mais dificultoso de reestruturação desse parâmetro na Área de Exporação Tradicional, possivelmente em fução do desgaste biótico ocasionado pela aplicabilidade de técnicas inapropriadas de exploração vegetacional.

\subsubsection{IVC - Índice de Valor de Cobertura}

\section{Área de Proteção Permanente}

Observa-se na Figura 9 que as 5 (cinco) primeiras espécies de maior atributo de IVC mantiveram-se em colocação estáveis durante os anos monitorados. As 17 espécies de maior IVC só começam a manifestar alteração em suas colocações no rank a partir de 1995, mas com pouco variação. As demais espécies apresentaram alguma variação na colocação do rank, mas sem alterações drásticas. Portanto, percebe-se uma real manutenção destas nessa área.

\section{Área de Exploração Planejada}




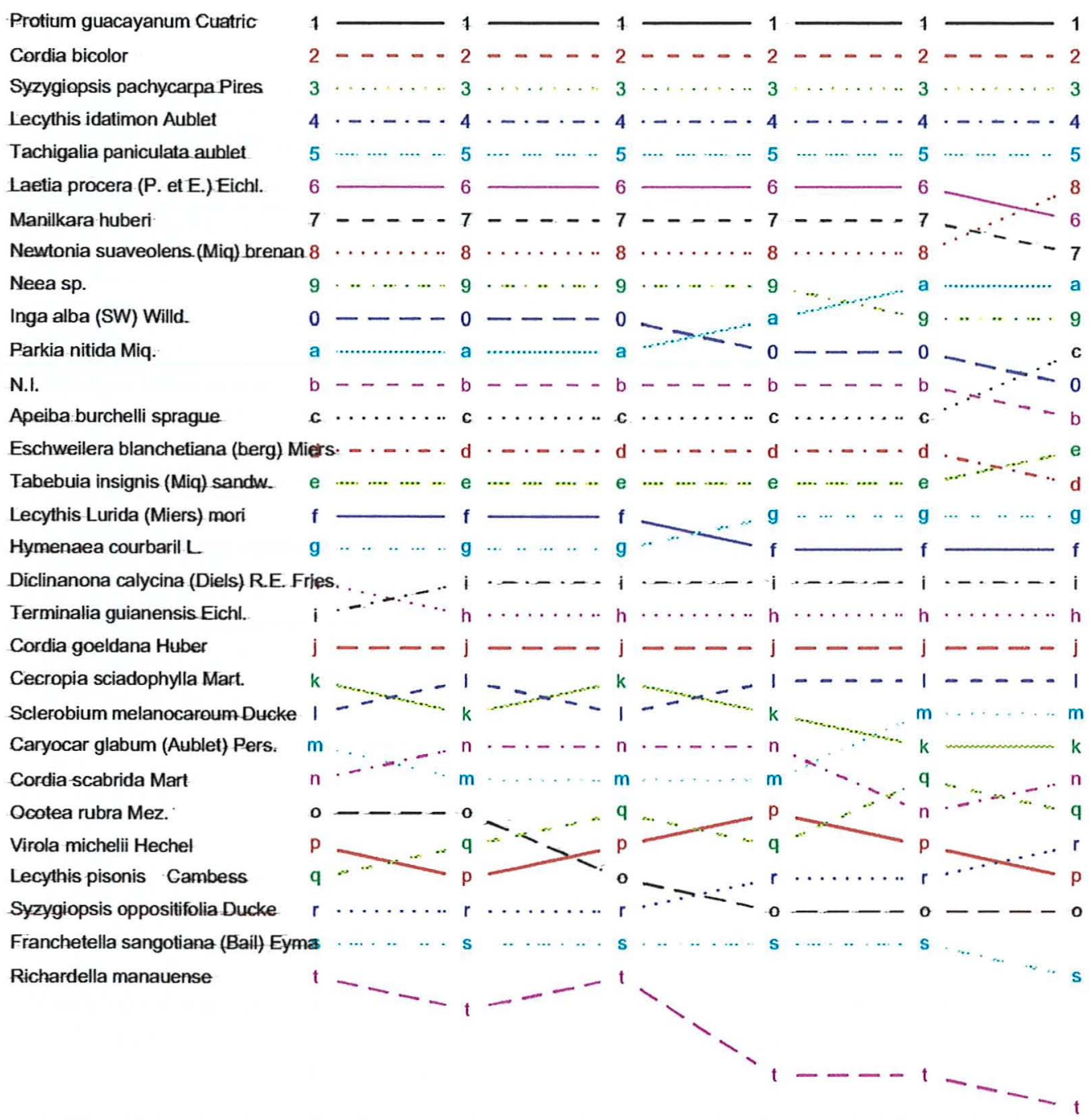

Figura 9 - Rank de IVC das 30 espécies de maior atributo desse parâmetro na Área de Proteção Permanente, nos anos de 1993, 1994, 1995, 1996, 1998, 2000 


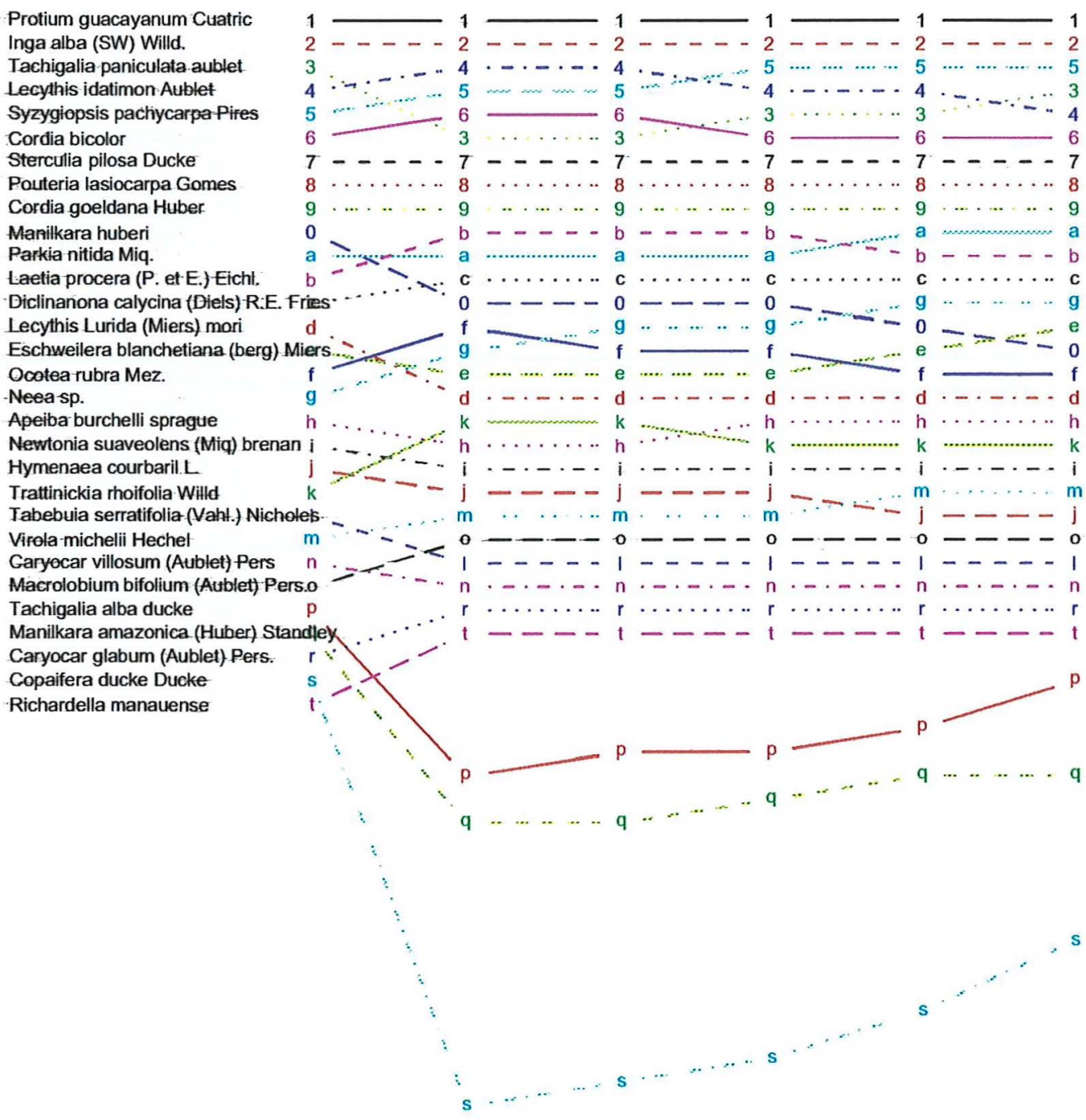

Figura 10-Rank de I甘G das 3 - espéeies de maior atributo desse parâmetro na Área de Exploração Planejada, nos anos de 1993, 1994, 1995, 1996, 1998, 2000 
$\mathrm{Na}$ Figura 10 observa-se que o Protium guacayanum (Breu manga) e a Inga alba (Ingá vermelha) não apresentam alteração em suas colocações por possuirem altos atributos de Densidade e Dominância relativa.

As espécies Tachigalia paniculata (Tachi preto), Lecythis idatimon (Jetereu) e a Syzigiopsis pachycarpa (Abiu amarelo) manifestaram alternância em suas colocações no rank. Isso ocorreu, possivelmente, em decorrência dos atributos de Dominância e Densidade relativa destas relacionados ao potencial adaptativo de cada uma.

As espécies Tachigalia alba Ducke (Tachi branco), Manilka amazonica (Maparajuba) e Copaifera ducke (Copaiba), espécies de alto valor econômico no mercado madereiro, apresentaram queda no rank após o processo de extração e uma lenta recolocação no rank ao longo dos anos. A espécie Manilkara huberi (Maçaranduba), de alto valor no mercado madereiro, apresentou ligeira queda no rank, após a intervenção estabilizou-se na mesma colocação por dois anos e retornou a cair. Portanto, merece especial atenção afim de não por em risco sua importância. Essa situação também não é diferente para a espécie Hymenaeae courbaril (Jatobá).

\section{Área de Exploração Tradicional}

A Figura 11 apresenta a variação de colocação das espés, ao longo dos anos na área de Exploração Tradicional, e revela uma drástica perda no atributo de IVC para a espécie Manilkara huberi (Maçaranduba), que apresenta recomposição a partir de 5 anos da intervenção, mas que necessita de cuidados e atenção antes da tomada de decisão na atividade de exploração.

A Hymeneae courbariu (Jatoba), Syzygiopsis oppositifolia Ducke (Abiu branco) e Ocotea rubra (Louro vermelho) apresentaram drásticas perdas em suas colocações posteriormente a intervenção. Com excessão do Abiu branco, que apresenta tendência de recolocação ao longo do tempo, as outras duas apresentam baixa recolocação.

A Inga microcalix (Ingávermelha), também requerida no mercado madeireiro, apresenta curiosa variação de sua colocação no rank, ou seja, apresenta 


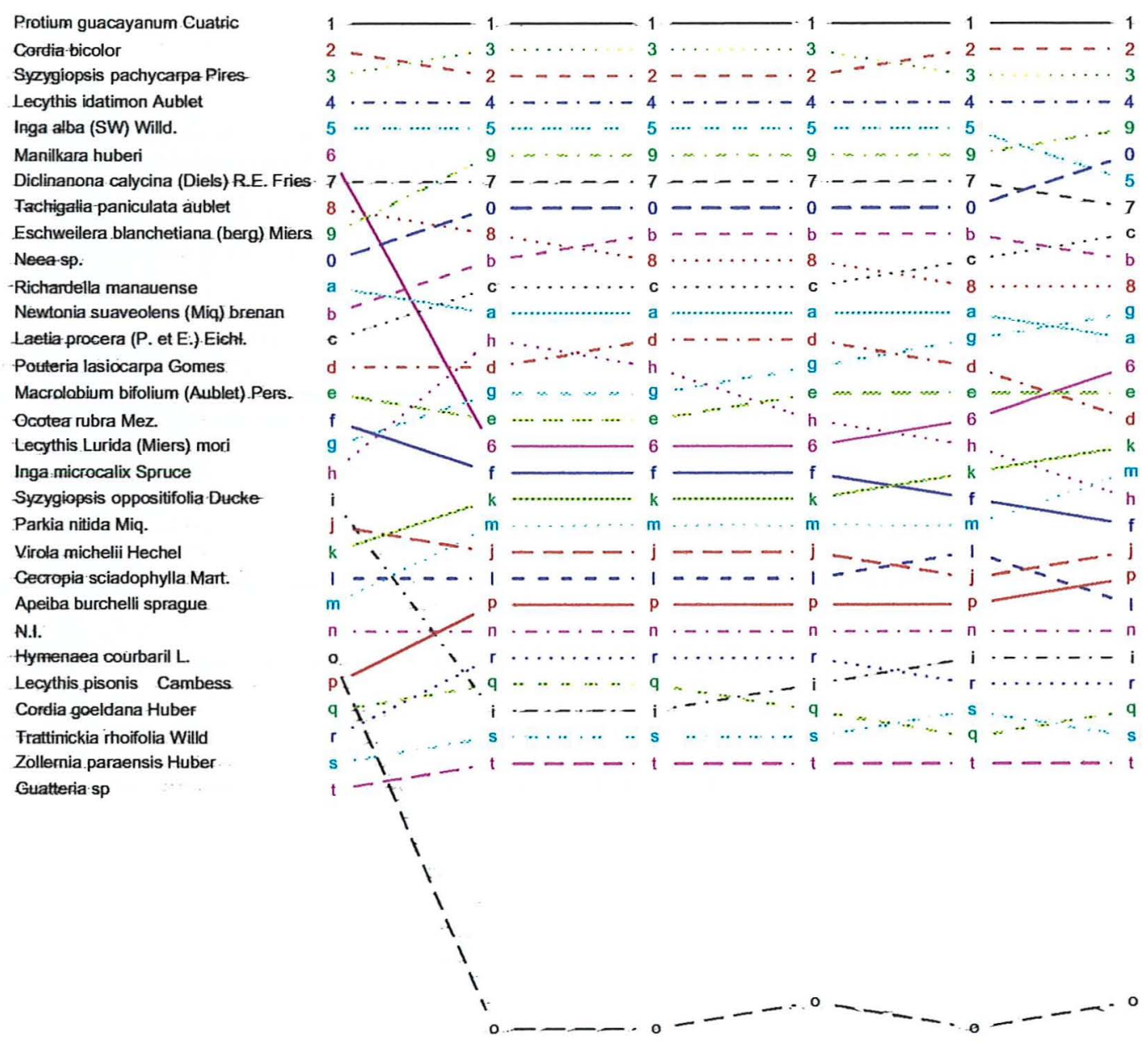

Figura 11 - Rank de $1 V$ Cas 30'espécies de maior atributo desse parâmetro na Área de Exploração Tradicional, nos anos de 1993, 1994, 1995, 1996, 1998, 2000 
elevação nesse atributo no ano seguinte a intervenção e drástica queda dessa colocação nos anos seguintes.

A Virola michelii apesar de ser uma espécie de grande interesse, devido seu alto valor madeireiro, apresentou elevação de sua colocação no rank ao longo dos anos possivelmente por ter sido preservada durante a intervenção ou por apresentar ao poder de adaptabilidade as alterações.

\subsection{Perdas na Exploração Tradicional}

Nesse tratamento houve a extração de 1093 indivíduos, com Dominância Absoluta total de $13.67 \mathrm{~m}^{2} h \mathrm{a}^{-1}$ em 1993. A espécie que teve a maior perda relativa, entre 1993 e 2000, em número de indivíduos (109 ind ou $53.4 \%$ de seus ind) foi a Inga alba (SW) Willd. (MIMOSACEAE), apesar do atributo desse seu parâmetro (191 ind) não ter sido o maior, em relação as demais, em 1993.

A espécie que apresentou o maior atributo de Densidade Absoluta em 1993 foi a Inga alba (SW) Willd (MIMOSACEAE), com 16.61 ind ha ${ }^{-1}$. Entretanto, nã obteve a mesma colocação quando o parâmetro foi Dominância Absoluta e obteve $0.43 \mathrm{~m}^{2} h \mathrm{a}^{-1}$. Essa espécie teve redução no atributo desses parâmetros no ano posterior a intervenção para 14.2 ind $h a^{-1}$ e $0.33 \mathrm{~m}^{2} h \mathrm{a}^{-1}$, havendo ainda mais redução em 2000 quando o valor de DA assume 11.67 ind $h a^{-1}$ e de DOA de $0.26 m^{2} h a^{-1}$.

Outra espécie que também apresentou redução bastante significativa em sua densidade foi a Tachigalia paniculata Aublet (CAESALPINACEAE). Esta espécie teve densidade absoluta de $6.28 \mathrm{ind} h \mathrm{a}^{-1} \mathrm{em} \mathrm{1993}$, reduzindo para $4.69 \mathrm{ind} h \mathrm{a}^{-1}$ em 1994 e 3.34 ind $h a^{-1}$ em 2000. Seu atributo de Dominância Absoluta em 1993 foi de $0.28 \mathrm{~m}^{2} h \mathrm{a}^{-1}$, reduzindo para $0.18 \mathrm{~m}^{2} h \mathrm{a}^{-1}$ em $1994 \mathrm{e}$ apresentando pequena elevação para $0.19 \mathrm{~m}^{2} h a^{-1} \mathrm{em} 2000$.

Organizando as cifras: 26 espécies tiveram perda, ao longo dos 7 anos, maior ou igual a $50 \%$ de seus indivíduos medidos em 1993. Dessas, 10 tiveram perda de $100 \%$, das quais somente o Brosimum potabile Ducke (MORACEAE) apresentou 2 individuos e as demais somente 1 indivíduo (ANEXO 3). 46 espécies apresentaram 
entre $10 \%$ e $29.9 \%$ de perda de seus ind. 24 espécies tiveram perda entre $30 \%$ e $49.9 \%$ e 20 espécies não tiveram perdas.

4 Famílias (MELIACEAE, ANACARDIACEAE, CARICACEAE e COMBRETACEAE) tiveram perdas maior ou igual a $50 \%$ de seus ind. 12 (CECROPIACEAE, RUTACEAE, LAURACEAE, MIMOSACEAE, MORACEAE, BIGNONIACEAE, FABACEAE, CAESALPINACEAE, GUTTIFERAE, STERCULIACEAE, ANNONACEAE, SAPOTACEAE) tiveram perdas entre $30 \%$ e $49.9 \%$. 17 (APOCYNACEAE, CARYOCARACEAE, ARALIACEAE, SIMARUBACEAE, BORAGINACEAE, EUPHORBIACEAE, TILIACEAE, LECYTHIDACEAE, HUMIRIACEAE, MYRISTICACEAE, BOMBACACEAE, EBENACEAE, FLACOURTIACEAE, BURSERACEAE, MELASTOMATACEAE, NYCTAGINACEAE, VIOLACEAE) tiveram perdas entre $10 \%$ e $29.9 \%$. Somente 3 Famílias (CELASTRACEAE, MALPIGHIACEAE, VOCHYSIACEAE) n ao tiveram perdas.

\subsection{Perdas Exploração Planejada}

Nesse tratamento houve a extração de 724 indivíduos, com Dominância Absoluta total de $13.9 \mathrm{~m}^{2} h \mathrm{a}^{-1}$. A espécie que teve a maior perda relativa, entre 1993 e 2000, em número de indivíduos (121 ind ou $29.7 \%$ de seus ind) foi a Inga alba (SW) Willd. (MIMOSACEAE), e o atributo desse seu parâmetro (407 ind) também foi o maior (em relação as demais) em 1993.

A espécie que apresentou o maior atributo de Densidade Absoluta em 1993 foi a Inga alba (SW) Willd. (MIMOSACEAE), com 16.61 ind ha ${ }^{-1}$. Entretanto, nã obteve a mesma colocação quando o parâmetro foi Dominância Absoluta e obteve $0.66 m^{2} h a^{-1}$. Essa espécie tem redução nos atributo desses parâmetros no ano posterior a intervenção para 14.2 ind $h a^{-1}$ e $0.62 \mathrm{~m}^{2} h \mathrm{a}^{-1}$, havendo ainda mais redução em 2000 quando o valor de DA assum $11.67 \mathrm{ind} h \mathrm{a}^{-1}$, mas apresenta um leve aumento de DOA de $0.64 m^{2} h a^{-1}$.

A segunda espécie que apresentou o maior parâmetro de densidade absoluta em 1993 foi a Protium guacayanum Cuatric (BURSERACEAE), com 221 
ind, perda de 62 ind. ou $28.1 \%$.

Organizando as cifras: 22 espécies tiveram perda, ao longo dos 7 anos, maior ou igual a $50 \%$ de seus indivíduos medidos em 1993. Dessas, a que tinha maior densidade absoluta em 1993 era a Cecropia sciadophylla Mart (CECROPIACEAE), com 29 ind. e perda de 14 ind. (ou 51.7\%). Todas as demais apresentaram densidade absoluta inferior a 9 ind.

10 espécies tiveram perda de $100 \%$, das quais a Miconia regelii (MELASTOMATACEAE) apresentou 3 individuos, a Abarema matarbifolia (Sandw) Barneby \& Eurimes apresentou 2 indivíduos e as demais somente 1 indivíduo.

15 espécies tiveram perda entre $30 \%$ e $49.9 \%$ de seus ind. 55 espécies tiveram perda entre $10 \%$ e $29.9 \%$. 8 espécies tiveram perda abaixo de $10 \%$ e 89 espécies não tiveram perdas.

2 Famílias (MELASTOMATACEAE, CELASTRACEAE) tiveram perda de $57.1 \%$ e $50 \%$ de seus ind consecutivamente. 5 (CECROPIACEAE, FABACEAE, COMBRETACEAE, RHAMNACEAE, RUTACEAE) tiveram perdas entre $30 \%$ e $49.9 \%$ de seus ind. 22 (ARALIACEAE, MIMOSACEAE, CARYOCARACEAE, SAPINDACEAE, ANACARDIACEAE, CAESALPINACEAE, LAURACEAE, MORACEAE, ANNONACEAE，APOCYNACEAE， BIGNONIACEAE, TILIACEAE, EUPHORBIACEAE, MELIACEAE, GUTTIFERAE, SIMARUBACEAE, HUMIRIACEAE，BORAGINACEAE， STERCULIACEAE, SAPOTACEAE, LECYTHIDACEAE, FLACOURTIACEAE) tiveram perdas entre $10 \%$ e $29.9 \%$ de seus ind. 4 (EBENACEAE, MYRISTICACEAE, BURSERACEAE, NYCTAGINACEAE) tiveram perdas entre 1\% e 9.9\% e 7 (BOMBACACEAE, CARICACEAE, CHRYSOBALANACEAE, DIDIAPETALACEAE, OLACACEAE, VIOLACEAE, VOCHYSIACEAE) não apresentaram perda alguma nesse período de tempo.

Houve redução no incremento basal no tratamento Exploração Planejada entre a medição antes da intervenção e o ano seguinte em $21.25 \mathrm{~m}^{2} h \mathrm{a}^{-1}$. Houve recuração desse parâmetro nos anos posteriores, apresentando somente $10.74 \mathrm{~m}^{2} h a^{-1}$ 
de diferença entre 1993 e 2000.

\subsection{Diversidade e estrutura comunitária dos tratamentos es- tudados}

Pelos resultados obtidos, supõem-se que ambos tratamentos não tiveram perdas na diversidade numa magnitude significante ao longo dos anos. Entretanto, as Figuras12, 13, 14 mostram uma pequena tendência na inclinação da curva da área de exploração tradicional que sugere redução nos índices. Entre os tratamentos as diferenças nos índices de diversidade foram estabelecidas antes das interveções e continuaram nos anos posteriores.

Foram recenseados 10982 árvores e arbustos e 228 espécies foram identificadas. O número de indivíduos amostrados por tratamento foi de 3135, 4152 e 3695 para a Área de Proteção Permanente, Exploração Planejada e Exploração Tradicional, respectivamente. Os valores de diversidade e equitabilidade apresentaram poucas variações de um tratamento para o outro, bem como entre os anos monitorados.

$\mathrm{Na}$ Área de Exploração Planejada foram encontradas, em 1993, 118 espécies, com $136.708 \mathrm{~m}^{2} h \mathrm{a}^{-1}$, com grau de equitabilidade em decrescimo, quando utilizado o parâmetro de dominância, em 1994 (logo após a intervenção) e elevação a partir de 1995; quando utilizado o parâmetro de densidade há somente elevação nesse grau. Na Área de Exploração Planejada foram encontradas 115 espécies, com $139.022 \mathrm{~m}^{2} h \mathrm{a}^{-1}$, e o grau de equitabilidade decresce em 1994 e estabiliza-se pelos próximos anos, quando utilizado o parâmetro de dominância e com valores muito parecidos com os da Área de Proteção; quando utilizado o parâmetro de densidade há somente uma elevação em 1994 com uma quase imperceptível elevação nos anos posteriores.

As famílias Sapotaceae, Mimosaceae, Lecythidaceae, Caesalpinaceae, Burseraceae e Boraginaceae foram responsáveis, sozinhas, por $67.9 \%$ de toda a 

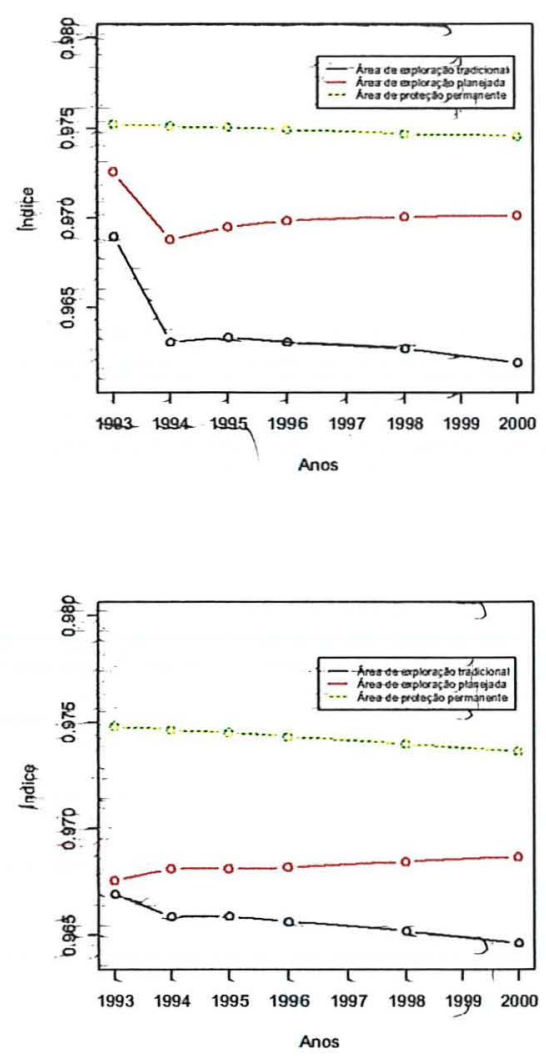

Fighra 12 - Índices de diversidade de Simpson para es três- tratamgntos, utilizando dominâneia (acima) e densidade (a baixo) como parâmetros

Dominância, $57.5 \%$ de toda a Densidade e $67.35 \%$ de todo o FVC analisados nos três tratamentos em 1993, antes das intervenções de extração.

No ano posterior a intervenção foi observado um decréscimo de 62.6 \% na representatividade da Dominância total das 6 Famílias citadas acima, em 1993. Entretanto, houve um acrécimo para de $66.8 \%$ na Densidade relativa a essas Famílias. Isso ocorreu em função da exclusão dos indivídıos de algumas Famílias após a Exploração. O- curioso foi que o FVC não alterou-se, sugerindo uma compensação no atributo desse parâmetro entre perda e ganho de Dominância e Densidade. Entre 1994 c 2000 houve a recomposição dessas Famílias cm rclação a 

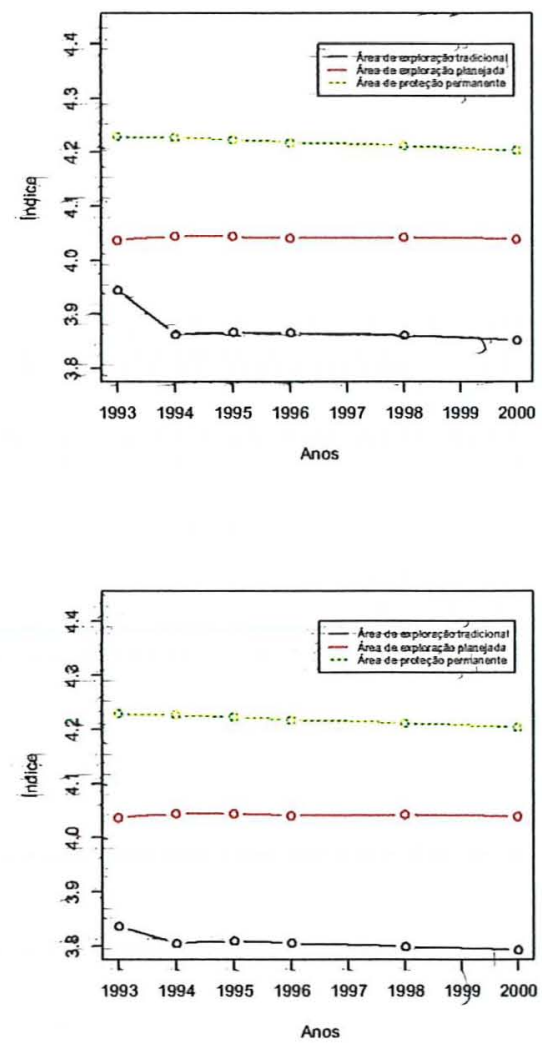

Figura 13 - Indices de diversidade de Shannon para os três tratamentos, Htilizando dominância (acima) e densidade (a baixo) como parâmetros

Dominância que se elevou pasra 68.1 \%, a Densidade para $67.1 \%$ de representatividade para todos os três tratamentos.

Portanto, foi observado que os tratamentos avaliados apresentaram composição florística extremamente diversificada.

$\mathrm{Na}$ Área de Exploração Planejada observou-se um rearranjo da vegetação ao longo dos 7 anos, com reestabelecimento de espécies recrutadas na extração e incremento basal total em ascensão. Isso provavelmente ocorreu devido o levantamento prévio da vegetação ocorrente e seleção de espécies para extração que não comprometessem a diversidade das Famílias, bem como o cstudo c organização no 
Tabela 6. Indice de Shannon - Winer para os tratamentos em todos os anos de medições

\begin{tabular}{cccc}
\hline ano & APP & AEP & AET \\
\hline 1993 & 4.228877 & 4.036109 & 3.835644 \\
1994 & 4.226396 & 4.043794 & 3.804373 \\
1995 & 4.222549 & 4.043794 & 3.808924 \\
1996 & 4.218598 & 4.040102 & 3.805482 \\
1998 & 4.216371 & 4.042464 & 3.798607 \\
2000 & 4.207775 & 4.039027 & 3.792993 \\
\hline
\end{tabular}

planejamento do processo de exploração, através do mapeamento das espécies no auxilio a dinamização desse processo.

$\mathrm{Na}$ Área de Exploração Tradicional o rearranjo da vegetação apresentou dificuldades no estabelecimento das espécies recrutadas para extração, possivelmente em função do descuido nesse recrutamento, ou seja, houve aplicação de técnicas inapropriadas ao estimulo e manutenção de espécies perenes, inserção na floresta sem conhecimento prévio da localização das espécies de interesse, corte e queda direcional das árvores em detrimento a comunidade presente no entorno, utilização de equipamentos prejudiciais e de estímulo à compactação do solo que também é promovido pelo arrastes das toras.

Todas essas atividades descritas foram fonte de grande influência nas mudanças da estrutura da vegetação, composição e diversidade das espécies ao longo do tempo. Apesar de sabido que toda intervenção, por menos impactante que que seja, estará de alguma forma influenciando nessas mudanças a partir de estímulos danosos ou benéficos. Portanto, na Área de Exploração Planejada percebeu-se distribuição espacial equilibrada das espécies, a partir das diferentes distribuições diamétricas. Isso também foi percebível em menor intensidade na Área de Exploração Tradicional. 
Tabela 7. Índice de Simpson para os tratamentos em todos os anos de medições

\begin{tabular}{cccc}
\hline ano & APP & AEP & AET \\
\hline 1993 & 0.9747937 & 0.9675415 & 0.9669220 \\
1994 & 0.9746228 & 0.9681052 & 0.9658694 \\
1995 & 0.9744956 & 0.9681052 & 0.9658808 \\
1996 & 0.9743052 & 0.9681825 & 0.9656215 \\
1998 & 0.9739660 & 0.9684367 & 0.9651951 \\
2000 & 0.9736101 & 0.9686705 & 0.9646210 \\
\hline
\end{tabular}

Em ambos tratamentos a composição e diversidade da vegetação se manteve, apesar de que em níveis diferentes, ou seja, a Área de Proteção Permanente, que serviu para comparação entre as outras duas, apresentou $H^{\prime}=4.22(1993)$ e 4.20 (2000); a Área de Exploração Planejada apresentou $H^{\prime}=4.03$ (1993) e 4.03 (2000) e a Área de Exploração Tradicional apresentou $H^{\prime}=3.83$ (1993) e 3.79 (2000). Esse resultado sugere que as técnicas adotadas na exploração planejada exercem um efeito positivo a vegetação maior que os efeitos exercidos pelas técnicas adotadas na exploração tradicional.

Entretanto, para confirmar efeitos de maior estimulo e de menor comprometimento a diversidade vegetacional é necessário uma avaliação por um tempo mais longo em ambos tratamentos, pois a literatura científica que acompanha trabalhos similares aponta para respostas a longo prazo sobre os impactos a vegetação por atividade humana.Entretanto é provável que, por não causar grande impressão danosa à vegetação, até o presente estudo, as técnicas de planejamento adotadas na exploração desponta se comparada ao "sistema"tradicional de extração de madeira adotado nessa região. 


\section{CONCLUSÃO}

Há variações e diferenças na estrutura populacional da vegetação entre os tratamentos antes da exploração, mas não percebeu-se grande variação na magnitude das alterações entre os tratamentos.

Houve melhor recomposiçãò da cobertura na área submetida a exploração planejada que na área submetida a exploração predatória, sugerindo a utilização dessas técnicas em trabalhos de exploração para a essa região.

Ainda não foi possível chegar a uma conclusão incisiva sobre o reflexo dos regimes de perturbações exercidos pelas práticas de Extração Tradicional e Extração Planejada sobre as espécies vegetacionais dessa área.

A estrutura e composição da vegetação e diversidade das espécies nas áreas submetidas a Exploração Planejada e Tradicional não apresentaram mudanças drásticas entre o periodo que antecede o processo exploratório até as últimas medições do ano 2000 . 
Anexos 


\section{ANEXO A - Composição da Vegetação em todos os 3 Tratamentos}

\begin{tabular}{|c|c|c|}
\hline Nome vulgar & Nome Cientifico & FAMILIA \\
\hline Saboeiro & Abarema jupunba (Wild.) & MIMOSACEAE \\
\hline Ingá rosca & Abarema matarbifolia (Sandw) Barneby \& Eurimes & MIMOSACEAE \\
\hline Louro preto folha brihante & Aioea att. densiflora Nees & LAURACEAE \\
\hline Louro folha verticilada & Aiouea sp & LAURACEAE \\
\hline Mapucuxi vermelho & Albizia pedicelaris & MIMOSACEAE \\
\hline Espeturana trifoliar & Allophylus nobustus Radlk & SAPINDACEAE \\
\hline Caju açcu & Anacardium giganteum Hanc. Ex Engl. & ANARCADEACEAE \\
\hline Envira sombrera & Arnona sp & ANNONACEAE \\
\hline Pente de macaco folha peluda & Apeiba albiflora sprague & TILIACEAE \\
\hline Pente de macaco & Apeiba burchelli sprague & TILIACEAE \\
\hline Pente de macaco sulcado & Apeiba burchelli sprague & TILIACEAE \\
\hline Envira pente de macaco & Apeiba echinata Gaertn & TILIACEAE \\
\hline Pente de macaco serrado & Apeiba echinata Gaertn & THLIACEAE \\
\hline Araracanga & Aspidosperma album Jacq. & APOCYNACEAE \\
\hline Carapanaúba & Aspidospetma auriculata & APOCYNACEAE \\
\hline Maparana & Aspidosperma inundatum Ducke & APOCYNACEAE \\
\hline Muiracatiara & Astronium leciontei Ducke & ANACARDIACEAE \\
\hline Pau branco & Auxemma oncocalyx (F. Allem) Taub. & EUPHORBIACEAE \\
\hline Tatajuba & Bagassa guianensis Aublet & MORACEAE \\
\hline Goiaba de anta & Bellucia grosstearoides & MELASTOMATACEAE \\
\hline Murucí & Birsonimia nerugo & MALPIGHIACEAE \\
\hline Imbiriçu & Bombax longepidecelata & BOMBACACEAE \\
\hline Imbiruçu (FBTF) & Bombax longepidecelata & BOMBACACEAE \\
\hline Mamorana terra firme & Bambax paraensis Ducke & BOMBACACEAE \\
\hline Sucupira & Bowdichia nitida Spruce ex Benth & FABACEAE \\
\hline Sucupira amarela & Bowdichia nitida Spruce ex Benth & FABACEAE \\
\hline Sucupira preta & Boudichia virgiloides H. B. K. & FABACEAE \\
\hline Janitá & Brosimum gutanensis Aubl. & MORACEAE \\
\hline Mururé & Brosimum obovata L. & MORACEAE \\
\hline Amapá & Brosinum potabile Ducke & MORACEAE \\
\hline Amapá amarelo & Brosimum potabile Ducke & MORACEAE \\
\hline Jacareúba & Calophyllum brasiliense Camb. & GUTTIFERAE \\
\hline Louro tamaquare & Caraipa richardiana Camb. & GUTTIFERAE \\
\hline Tamaquaré & Caraipa richardiana Camb. & GUTTIFERAE \\
\hline Andiroba. & Carapa guianensis Aubl. & MELIACEAE \\
\hline Piquiarana & Caryocar glabum (Aubl) Pers. & CARYOCARACEAE \\
\hline Piquiá & Caryocar villosum (Aubl) Pers & CARYOCARACEAE \\
\hline Embaúba casca vermelha & Cecropia destaque & CECROPIACEAE \\
\hline Embaúba branca & Cecropia obtusa & CEGROPIACEAE \\
\hline Embaúba & Cecropia sciadophylla Mart. & CECROPIACEAE \\
\hline Cedro & Cedrela odorata $\mathbf{L}$. & MELIACEAE \\
\hline Cedro vermelho & Cedrela odorata $\mathbf{L}$. & MELIACEAE \\
\hline Balaio de cutia & Chamaecrista xinguensis & CAESALPINACEAE \\
\hline Paul vermelho & Chaunochiton Kappleri (Sag. Ex Engl.) Ducke & OLACACEAE \\
\hline Guariuba & Clarisa racemosa Ruiz e Pav. & SAPOTACEAE \\
\hline Copaíba & Copaifera ducke & CAESALPINIACEAE \\
\hline Freijo branco & Cardia bicolor & BORAGINACEAE \\
\hline Freijó cinza & Cordia goeldana Huber & BORAGINACEAE \\
\hline Freijó & Cordia sagoti L. M. Johnston & BORAGINACEAE \\
\hline Freijozinho & Cordia scabrida Mart & BORAGINACEAE \\
\hline Pajurazinho & Gouepia bracteosa Benth. & CHRYSOBALANACEAE \\
\hline Tauari & Coumtari guinnensis Aubl. & LEGYTHIDACEAE \\
\hline Tauari/estoupeiro folha grande & Couratari guianensis Aubl. & LECYTHIDAGEAE \\
\hline Tauari/estopeiro folha peluda & Cuaratari oblongfolia Ducke et Knuth & LECYTHIDACEAE \\
\hline Tauari/estopeiro folha pequena & Cuoratari oblongfolia Ducke et Knuth & LECYTHIDACEAE \\
\hline Estoupeiro & Cuoratari ablongfolia Ducke et Knuth & LECYTHIDACEAE \\
\hline Espeturana peluda & Cuparia hirsuta Radlk & SAPINDACEAE \\
\hline
\end{tabular}


ANEXO A - Composição da Vegetação em todos os 3 Tratamentos (cont.)

\begin{tabular}{|c|c|c|}
\hline None vulgar & Nome Científico & FAMÍLIA \\
\hline Espeturana & Cupania scrobiculata L. C. Rich & SAPINDACEAE \\
\hline Jutaj pororoca & Dialium guianesis (Aublet.) Sandwith & GAESALPINIACEAE \\
\hline Envira preta & Diclinanona calycina (Diels) R.E. Fries & ANNONACEAE \\
\hline Louro cravo & Dicypellium caryophyllatum Nees & ARALIACEAE \\
\hline Morototó & Didymopanax morototoni (Aubl) Decne \& Planch. & ARALIACEAE \\
\hline Caqui preto & Diospyros ducke Sandw & EBENACEAE \\
\hline Caqui follha branca & Diospyros melinoni (Hiern) A. Smith & EBENACEAE \\
\hline Caqui & Diospyros pratermissa Sandwith & EBENACEAE \\
\hline Caqui casca dura & Diospyros tectranda Hiern & EBENACEAE \\
\hline Mangabarana folha pequena & Dipllon venezuelana Aublet & SAPOTACEAE \\
\hline Cumaru & Dipteryx odorata Willd & FABACEAE \\
\hline Envira surucucu & Duguetia echynoflora & ANNONACEAE \\
\hline Caniseiro & Duguetia flagellaris & ANNONACEAE \\
\hline Curupira falsa & Dulacea sp. & OLACACEAE \\
\hline Abiu folha peluda & Ecclinusa abbreviata Ducke & SAPOTACEAE \\
\hline Guajará branco & Elaeoluma glabrescens (Mart \& End1) Aubr Pelleg & SAPOTACEAE \\
\hline Uxi & Endopleura uchi (Huber) Cuatr. & HUMIRIACEAE \\
\hline Orelha de macaco & Enterolobium schomburgkii (Benth.) Benth & MIMOSACEAE \\
\hline Muirapiranga & Eperua schonburgkiana Benth. & MELIACEAE \\
\hline Mamorana & Eriotheca globosa (Aubl.) Robyns & BOMBACACEAE \\
\hline Feijão bravo & Erytrina fusch Lour & FABACEAE \\
\hline Ripeiro & Eschweilera apiculata & LECYTHIDACEAE \\
\hline Mata mata preto & Eschweilera blanchetiana (berg) Miers & LECYTHIDACEAE \\
\hline Mata matá jibóia & Eschweilera collina Eyma & LECYTHIDACEAE \\
\hline Mata matá branco & Eschweilera coriaceae (A. P. ecandole) Martius ex Berg & LECYTHIDACEAE \\
\hline Mata matá grande forum & Eschweilera grandeflorum & LECYTHIDACEAE \\
\hline Mata matá & Eschweilera pedicelata & LECYTHIDACEAE \\
\hline Pau amarelo & Euxylophora paraensis Huber & RUTACEAE \\
\hline Abiu seco folha grande & Franchetella jariense & SAPOTACEAE \\
\hline Guajará mole & Franchetello sangotiana (Bail) Eyma & SAPOTACEAE \\
\hline Guajarana mole & Franchetella sangotiana (Bail) Eyma & SAPOTACEAE \\
\hline Guajararana & Franchetella $\mathrm{sp}$ & SAPOTACEAE \\
\hline Envira preta 3 & Gatteria schomburgkiana Mart & ANNONACEAE \\
\hline Envira preta folha peluda & Gatteria schomburgkiana Mart & ANNONACEAE \\
\hline Envira preta folha pequena & Gatteria schomburgkiana Mart & ANNONACEAE \\
\hline Abiu casca doce & Glicoxilo sp & SAPOTACEAE \\
\hline Andirobarana folla peluda & Guarea carinata Ducke & MELIACEAE \\
\hline Andirobarana folha grande & Guarea kunthiana A.Juss. & MELIACEAE \\
\hline Janaúba & Guarea sp. & MELIACEAE \\
\hline Laranjinha & Guatteria citriodora Ducke & ANNONACEAE \\
\hline Envira preta folha grande & Guatteria olivacea R. E. Fries & ANNONACEAE \\
\hline Envira preta casca grossa & Guatterio poeppigiana Mart. & ANNONACEAE \\
\hline Envira vermelha & Guatteria sp & ANNONAGEAE \\
\hline Mão de gato & Helicostylis pedunculata R. Bem & MORACEAE \\
\hline Sucuuba & Himatanthus sucuuba (Spruce)Woodson & APOCYNACEAE \\
\hline Jutaí mirim & Himenaea palustris Ducke & CAESALPINIACEAE \\
\hline Jutaí mirim (vermelho) & Himenaea parvifolia Huber & CAESALPINIACEAE \\
\hline Angelim pedra & Himenolobium pulchetrimum Ducke & MIMOSACEAE \\
\hline Jatoba & Hymenaea courbaril L. & CAESALPINIACEAE \\
\hline Jatoba verdadeiro & Hymenaea courbaril L. & CAESALPINIACEAE \\
\hline Jutai açu & Hymennen courbaril L. & CAESALPINIACEAE \\
\hline Jutai & Hymenaea oblongfolia Huber & CAESALPINIACEAE \\
\hline Ingá bourgoni & Inga acreana Harus & MIMOSACEAE \\
\hline Inga alba & Inga alba (SW) Willd. & MIMOSACEAE \\
\hline Inga vermelha & Inga alba (SW) Wilid. & MIMOSACEAE \\
\hline Inga vermelha (xixi) & Inga alba (SW) Willd. & MIMOSACEAE \\
\hline
\end{tabular}


ANEXO A - Composição da Vegetação em todos os 3 Tratamentos (cont.)

\begin{tabular}{|c|c|c|}
\hline Nome vulgar & Nome Científico & FAMILIA \\
\hline Inga vermelha 1 & Inga alba (SW) Willd. & MIMOSACEAE \\
\hline Inga vermelha 1 (xixi) & Inga alba (SW) Willd. & MIMOSACEAE \\
\hline Inga facãoozinho & Inga aplendens Willd & MIMOSACEAE \\
\hline Inga capitata & Inga capitata Desv. & MIMOSACEAE \\
\hline Inga branca & Inga $C F$. cylindrica Mart & MIMOSACEAE \\
\hline Inga cilíndrica & Inga $C F$, pezizifern Benth & MIMOSACEAE \\
\hline Inga sulcado & Inga CF. strigillosa Spr. Ex Benth & MIMOSACEAE \\
\hline Inga da várzea & Inga dumosa Bth & MIMOSACEAE \\
\hline Inga maguinata & Inge dumosa Bth & MIMOSACEAE \\
\hline Inga cipo & Inga edulis Mart & MIMOSACEAE \\
\hline Inga estípula pequena & Inga falcistipula Ducke & MIMOSACEAE \\
\hline Inga coração de preguiça & Inga gracilifolia Benth & MIMOSACEAE \\
\hline Inga folha grande & Inga macrophylla H.В.К. & MIMOSACEAE \\
\hline Inga de sangue & Inga microcalix Spruce & MIMOSACEAE \\
\hline Inga vermelha & Inga microcalix Spruce & MIMOSACEAE \\
\hline Inga folha peluda & Inga rubiginosa (Rich) DC. & MIMOSACEAE \\
\hline Inga rubiginasa & Inga rubiginosa (Rich) DC. & MIMOSACEAE \\
\hline Inga vermelha folha peluda & Inga rubiginosa (Rich) DC. & MIMOSACEAE \\
\hline lnga & Inga sp. & MIMOSACEAE \\
\hline Inga folha pequena & lnga sp. & MIMOSACEAE \\
\hline Inga de roçado & Inga thibaldiana DC. & MIMOSACEAE \\
\hline Pará pará & Jacaranda copaia (Aublet) D. Don & BIGNONIACEAE \\
\hline Mamui & Jacaratia espinosa & CARICACEAE \\
\hline Papo de mutum & Lacunaria fenmanii (Oliv.) Ducke & QUIINACEAE \\
\hline Pau jacaré & Laetia procera (P. et E.) Eichl. & FLACOURTIACEAE \\
\hline Mata matá casca lisa & Lecythis chartacea Berg & LECYTHIDACEAE \\
\hline Jatereu & Lecythis idatimon Aublet & LECYTHIDACEAE \\
\hline Jatereu folha grande & Lecythis idatimon Aublet & LECYTHIDACEAE \\
\hline Jarana & Lecythis Lurida (Miers) mori & LECYTHIDACEAE \\
\hline Sapucaia & Lecythis pisonis Cambess & LECYTHIDACEAE \\
\hline Macucu & Licania heteromorpha Bth. & CHRYSOBALANACEAE \\
\hline Macucu de sangue & Licania heteromorpha Bth. & CHRYSOBALANACEAE \\
\hline Pintadinho & Licania pallida Spruce ex Sagot & CHRYSOBALANACEAE \\
\hline Louro amarelo & Licaria rigida Kosterm & LAURACEAE \\
\hline Iperana bifoliar & Macrolobium angustifolium (Benth) Covsn & CAESALPINACEAE \\
\hline Iperana & Macrolobium bifolium (Aublet) Pers. & CAESALPINACEAE \\
\hline Iperana folha composta & Macrolobium campestre Hub. & CAESALPINACEAE \\
\hline Iperana composta & Macrolobium campestre Hub. & CAESALPINACEAE \\
\hline Iperana folha miúda & Macrolobium campestre Hub. & CAESALPINACEAE \\
\hline Maparajuba & Manilkara amazonica (Huber) Standley & SAPOTACEAE \\
\hline Macaranduba & Manilkare huberi & SAPOTACEAE \\
\hline Macarandubinha & Manilkara paraensis & SAPOTACEAE \\
\hline Chichua & Moytenus guianensis K. L. & CELASTRACEAE \\
\hline Tinteiro & Miconia regelii & MELASTOMATACEAE \\
\hline Seringarana & Micrandra elata Benth & EUPHORBIACEAE \\
\hline Mangabarana folha peluda & Micropholis guianensis (A. DC) Pierre & SAPOTACEAE \\
\hline Currupixa & Micropholis melinorianum & SAPOTACEAE \\
\hline Aquariquara & Minquartia guianensis Aubl. & OLACACEAE \\
\hline Anani da Terra Firme & Moronobea coccinea Aubl. & GUTTIFERAE \\
\hline Bacuri Falso & Moronobea coccinea Aubl. & GUTTIFERAE \\
\hline Goiabinha & Mouriria guianensis Aubl. & MELASTOMATACEAE \\
\hline Louro de tamanco & Neciandra cuspidata Nees & LAURACEAE \\
\hline Louro tamanco & Nectandra cuspidata Nees & LAURACEAE \\
\hline Louro puxurí bravo & Nectandra grandis Mez. & LAURACEAE \\
\hline Louro & Nectandra pichurim Mez. & LAURACEAE \\
\hline João mole & Neea sp. & NYCTAGINAGEAE \\
\hline
\end{tabular}


ANEXO A - Composição da Vegetação em todos os 3 Tratamentos (cont.)

\begin{tabular}{|c|c|c|}
\hline Nome vulgar & Nome Científico & FAMÍLIA \\
\hline Guajará pedra & Neoxythece elegans (A. DC.) Aubret & SAPOTACEAE \\
\hline Abiu farinha seca & Neoxythece elegans (A. DC.) Aubret & SAPOTACEAE \\
\hline Guajará & Neoxythece robusta (M. \& Eichl.) Aubr. \& Pell. & SAPOTACEAE \\
\hline Timborana folha grande & Newtonia psilostachya (DC) Brenan & MIMOSACEAE \\
\hline Timborara fotha peluda & Newtonia psilostachya (DC) Brenan & MIMOSACEAE \\
\hline Timborana & Nenutonin suaveolens (Miq) Brenan & MIMOSACEAE \\
\hline Timborana folha pequena & Nevtoria suaveolens (Miq) Brenan & MMOSACEAE \\
\hline Louro canelado & Ocotea cajumari & LAURACEAE \\
\hline Louro preto & Ocotea caudata Mez. & LAURACEAE \\
\hline Louro da folhona & Ocotea cernua (Nees) Mez & LAURACEAE \\
\hline Louro canela & Ocotea fragantissima Ducke & LAURACEAE \\
\hline Louro abacate & Ocoter glomerata (Nees) mez & LAURACEAE \\
\hline Louro branco & Ocotea guianensis Aublet & LAURACEAE \\
\hline Louro vermelho vincado & Ocotea longifolia H.B.K. & LAURACEAE \\
\hline Louro vincado & Ocoted longifalia H.B.K. & LAURACEAE \\
\hline Louro preto casca vermelha & Ocotea petalanthera (Meiss) Mez & LAURACEAE \\
\hline Louro vermelho & Ocotea rubra Mez. & LAURACEAE \\
\hline Buiuçu & Ormosia coutinhoi Ducke & FABACEAE \\
\hline Parimari & Parimari rodolphiz & CHRYSOBALANACEAE \\
\hline Faveira coré grande & Parkia gigantocarpa Ducke & MIMOSACEAE \\
\hline Faveira folha grande & Parkia gigantocarpa Ducke & MIMOSACEAE \\
\hline Faveira vermelha & Parkia multijuga Benth & MIMOSACEAE \\
\hline Faveira & Parkia nitida Miq. & MIMOSACEAE \\
\hline Faveira branca & Parkia nitida Miq. & MIMOSACEAE \\
\hline Espeturana & Parkia nitida Miq. & MIMOSACEAE \\
\hline Faveira bolota & Parkia pendula Benth Ex. Walp & MIMOSACEAE \\
\hline Faveira pêndula & Parkia pendula Benth Ex. Walp & MIMOSACEAE \\
\hline Faveira paricá & Parkia sp & MIMOSACEAE \\
\hline Moiratinga & Perebea guicnensis Aubl & MORACEAE \\
\hline Angelim rajado & Pithecolobium racemosum & MIMOSACEAE \\
\hline Macacaúba & Platymiscium filipes Benth & FABACEAE \\
\hline Gema de ovo & Poecilanthe effusa (Huber) Ducke & FABACEAE \\
\hline Embaúba benguê & Pouroma guianensis & CECROPIACEAE \\
\hline Embaúba torém & Pourouma minar & CECROPIAGEAE \\
\hline Abiu & Pouteria caimito (R\&P) Radek & SAPOTACEAE \\
\hline Abiu vermelho & Pouteria esprucia & SAPOTACEAE \\
\hline Abiu preto & Pouteria Krukovii (A.C. Smith) Baehni & SAPOTACEAE \\
\hline Abiu seco & Pouteria lasiocarpa Gomes & SAPOTACEAE \\
\hline Abiu cutiti & Pouteria macrophilla (A.DC) Eyma & SAPOTACEAE \\
\hline Abiu cutiti preto & Pouteria sp & SAPOTACEAE \\
\hline Abiu guajara & Pouteria sp & SAPOTACEAE \\
\hline Abiu sem casca & Pouteria sp & SAPOTACEAE \\
\hline Abiu solta casca & Pouteria sp & SAPOTACEAE \\
\hline Axnesclāo & Protium altsoni Sandw. & BURSERACEAE \\
\hline Amescla & Protium altsoni Sandw. & BURSERACEAE \\
\hline Breu amescla & Protium altsoni Sandw. & BURSERACEAE \\
\hline Breu vermelho & Protium decandrum (Aubl) March & BURSERACEAE \\
\hline Breu manga & Protium guacayanum Cuatric & BURSERACEAE \\
\hline Breu & Protium sagotianum March. & BURSERACEAE \\
\hline Breu branco & Protium sagotianum March. & BURSERACEAE \\
\hline Breu preto & Protium tennifolium Engl. & BURSERACEAE \\
\hline Mututi & Pierocarpus rohrii Vahl. & MORACEAE \\
\hline Mandioqueiro & Qualea cf. lancifolia Ducke & VOCHXSIACEAE \\
\hline Guajará preto & Radlkoferela macrocarpa (Huber) Aubr. & SAPOTACEAE \\
\hline Abiurana & Richardella manauense & SAPOTACEAE \\
\hline Abiurana folha peluda & Richandella manauense & SAPOTACEAE \\
\hline
\end{tabular}


ANEXO A - Composição da Vegetação em todos os 3 Tratamentos (cont.)

\begin{tabular}{|c|c|c|}
\hline Nome vulgar & Nome Cientifico & FAMILIA \\
\hline Quariquarana & Rinorea guianensis (Aubl) Schum. & VIOLACEAE \\
\hline Canela de velho & Rinorea macrocarpa (Mart.) O. Kuntze & VIOLACEAE \\
\hline Envira & Rollinia exsucca (Dun) A. DC. & ANNONACEAE \\
\hline Uxirana & Sacoglottis amazonica Benth & HUMIRIACEAE \\
\hline Guajarazinho & Sandwithiodoxa egregia (Sandw.) Aubr. \& Pelleg. & SAPOTACEAE \\
\hline Murupita & Sapium lanciolatum & EUPHORBIACEAE \\
\hline Ajarai & Sarcaulus brasiliensis Eyma & SAPOTACEAE \\
\hline Tachi & Sclerobium goeldianum Huber & CAESALPINIACEAE \\
\hline Tachi vermelho & Sclerobium melanocaroum Ducke & CAESALPINIACEAE \\
\hline Paricá & Shichozolobium amazonicum (Huber) Ducke & CAESALPINIACEAE \\
\hline Mata menino & Simarouba amata Aubl & SIMARUBACEAE \\
\hline Marupá & Simaruba amara Aubl & SIMARUBACEAE \\
\hline Murupá & Simaruba amara Aubl & SIMARUBACEAE \\
\hline Urucurana & Sloarea att.ternifora (Moc \& Sesse) Standl & EUPHORBIACEAE \\
\hline Tacacazeira & Sterculia pilosa Ducke & STERCULIACEAE \\
\hline Tacacazeira 2 & Sterculia pruriens (Aubl) K. Schum & STERCULIACEAE \\
\hline Tacacazeira 1 & Sterculia speciasa Schum & STERCULIACEAE \\
\hline Paricarauna & Stryphnodendran guianensis (Avbl) Sw & MIMOSACEAE \\
\hline Paricarana & Stryphnodendron guianensis (Aubl) Sw & MIMOSACEAE \\
\hline Tamaquaré & Stryphnodendron palystachium & MIMOSACEAE \\
\hline Tamaquaré 1 & Stryphrodendron paniculatum Popp \& Endl & MIMOSACEAE \\
\hline Pacapeuá & Swartzia recurva Poeppig & CAESALPINACEAE \\
\hline Bolacha & Syzygiopsis oppositifolia Ducke & SAPOTACEAE \\
\hline Guajará bolacha & Syzygiopsis oppositifolia Ducke & SAPOTACEAE \\
\hline Abiu branco & Syzygiopsis oppositifolia Ducke & SAPOTACEAE \\
\hline Abiu amarelo & Syzygiopsis pachycarpa Pires & SAPOTACEAE \\
\hline Abiu casca grossa & Syzygiopsis pachycarpa Pires & SAPOTACEAE \\
\hline Ipè roxo & Tabebuia insignis (Miq) sandw. & BIGNONIACEAE \\
\hline ipê & Tabebuia serratifolia (Vahl.) Nicholes & BIGNONIACEAE \\
\hline Ipê amarelo & Tabebuia serratifolia (Vahl.) Nicholes & BIGNONIACEAE \\
\hline Tachi branco & Tachigalia alba Ducke & CAESALPINIACEAE \\
\hline Tachi preto & Tachigalia paniculata Aubl & CAESALPINIACEAE \\
\hline Pitomba da mata & Talisia $C F$, intermedia Radlk & SAPINDACEAE \\
\hline Pitambarana & Talisia $C F$. intermedia Radlk & SAPINDACEAE \\
\hline Tapiririca & Tapinira guianensis Aubl & SAPOTACEAE \\
\hline Tapiririca vermelha & Tapirira guianensis Anbl & SAPOTACEAE \\
\hline Pau de bicho & Tapura amazonica Poep. et Eugl. & DIDIAPETALACEAE \\
\hline Tanimbuca folha pequena & Terminalia argentea & COMBRETACEAE \\
\hline Tanimbuca & Terminalia guianensis Eichl. & COMBRETACEAE \\
\hline Barrote & Tetragastris panamensis & BURSERACEAE \\
\hline Barrotinho & Tetragastris panamensis & BURSERACEAE \\
\hline Mangue & Tovomita brevistaminea (Mart), Walp & GUTTIFERAE \\
\hline Mangueirana & Tovomita brevistaminea (Mart). Walp & GUT'TIFERAE \\
\hline Breu sucuruba & Trattinickia thoifolia Willd & BURSERACEAE \\
\hline Faveira amarela & Vatairea paraensis Ducke & FABACEAE \\
\hline Ucuuba & Virola cuspidato Warb. & MYRISTICACEAE \\
\hline Ucuuba preta & Virola michelii Hechel & MYRISTICACEAE \\
\hline Virola & Virola michelii Hechel & MYRISTIGACEAE \\
\hline Ucuuba branca & Virola surinamensis (Rol.) Werb. & MYRISTICACEAE \\
\hline Lacräo & Vismia sp. & GUTTIFERAE \\
\hline Lacre & Vismia sp. & GUTTIFERAE \\
\hline Quaruba & Vochysia maxima Ducke & VOCHYSIACEAE \\
\hline Quaruba cedro & Vochysia surinamesis Staf. & VOCHYSIACEAE \\
\hline Envira branca & Xilopia nitida & ANNONACEAE \\
\hline Envira cana & Xilopia nitida & ANNONACEAE \\
\hline Tamanqueira folha grande & Zanthoxylum reguenelianum Engl & RUTACEAE \\
\hline
\end{tabular}




\begin{tabular}{|c|c|c|c|c|c|c|c|c|c|c|c|c|c|c|c|c|}
\hline & & DOA & & & DOR & & & $\mathrm{DA}$ & & & $\mathrm{DR}$ & & & IVC & & \\
\hline Familias & ${ }^{* 1993^{*}}$ & *1994** & ${ }^{*} 2000^{*}$ & ${ }^{*} 1993^{*}$ & ${ }^{* 1} 1994^{*}$ & ${ }^{*} 2000^{*}$ & $* 1993^{*}$ & $* 1994^{*}$ & ${ }^{*} 2000^{*}$ & ${ }^{*} 1993^{*}$ & *1994* & ${ }^{*} 2000^{*}$ & *1993* & ${ }^{* 1994^{*}}$ & $* 2000^{*}$ & Z \\
\hline MIMOSACEAE & 1.83 & 1.52 & 1.75 & 13.16 & 12.95 & 13.59 & 29.92 & 26.24 & 22.29 & 17.65 & 17.19 & 15.95 & 15.41 & 15.07 & 14.77 & [t] \\
\hline SAPOTACEAE & 2.28 & 1.83 & 1.96 & 16.43 & 15.57 & 15.22 & 22.33 & 20.2 & 19.22 & 13.17 & 13.23 & 13.76 & 14.8 & 14.4 & 14.49 & $x$ \\
\hline CAESALPINACEAE & 1.6 & 1.2 & 1.42 & 11.51 & 10.19 & 11.07 & 18.65 & 16.04 & 14.49 & 11.01 & 10.51 & 10.37 & 11.26 & 10.35 & 10.72 & \\
\hline LECYTHIDACEAE & 1.53 & 1.4 & 1.47 & 11 & 11.91 & 11.47 & 16.2 & 14.9 & 14.08 & 9.56 & 9.76 & 10.08 & 10.28 & 10.83 & 10.77 & $\varpi$ \\
\hline BURSERACEAE & 1.63 & 1.62 & 1.68 & 11.72 & 13.76 & 13.05 & 13.47 & 13.14 & 12.53 & 7.95 & 8.61 & 8.97 & 9.83 & 11.18 & 11.01 & 1 \\
\hline BORAGINACEAE & 0.72 & 0.65 & 0.71 & 5.19 & 5.54 & 5.5 & 14.73 & 13.67 & 12.65 & 8.69 & 8.95 & 9.05 & 6.94 & 7.25 & 7.28 & T. \\
\hline STERCULIACEAE & 0.24 & 0.24 & 0.29 & 1.75 & 2.04 & 2.27 & 7.92 & 7.22 & 6.82 & 4.67 & 4.73 & 4.88 & 3.21 & 3.38 & 3.58 & 8 \\
\hline LAURACEAE & 0.35 & 0.33 & 0.34 & 2.5 & 2.82 & 2.67 & 5.84 & 5.43 & 4.61 & 3.44 & 3.56 & 3.3 & 2.97 & 3.19 & 2.98 & 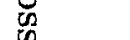 \\
\hline ANNONACEAE & 0.28 & 0.25 & 0.3 & 2.02 & 2.16 & 2.37 & 6.45 & 5.67 & 5.27 & 3.81 & 3.72 & 3.77 & 2.91 & 2.94 & 3.07 & क \\
\hline CARYOCARACEAE & 0.5 & 0.34 & 0.35 & 3.58 & 2.85 & 2.72 & 1.63 & 1.22 & 1.22 & 0.96 & 0.8 & 0.88 & 2.27 & 1.83 & 1.8 & . \\
\hline FLACOURTIACEAE & 0.29 & 0.29 & 0.32 & 2.1 & 2.44 & 2.49 & 3.88 & 3.63 & 3.39 & 2.29 & 2.38 & 2.42 & 2.19 & 2.41 & 2.46 & 7 \\
\hline BIGNONIACEAE & 0.37 & 0.25 & 0.29 & 2.66 & 2.15 & 2.25 & 2.12 & 1.8 & 1.76 & 1.25 & 1.18 & 1.26 & 1.96 & 1.66 & 1.75 & da \\
\hline NYCTAGINACEAE & 0.25 & 0.24 & 0.26 & 1.78 & 2.03 & 2.06 & 3.18 & 3.06 & 3.06 & 1.88 & 2 & 2.19 & 1.83 & 2.02 & 2.13 & 。. \\
\hline TILIACEAE & 0.16 & 0.15 & 0.19 & 1.17 & 1.3 & 1.5 & 3.59 & 3.18 & 2.98 & 2.12 & 2.09 & 2.13 & 1.64 & 1.69 & 1.82 & a. \\
\hline CECROPIACEAE & 0.22 & 0.18 & 0.15 & 1.58 & 1.55 & 1.19 & 2.41 & 1.92 & 1.35 & 1.42 & 1.26 & 0.96 & 1.5 & 1.4 & 1.08 & है \\
\hline MYRISTICACEAE & 0.14 & 0.14 & 0.17 & 1.04 & 1.19 & 1.35 & 3.18 & 2.98 & 2.9 & 1.88 & 1.95 & 2.07 & 1.46 & 1.57 & 1.71 & +1 \\
\hline MORACEAE & 0.22 & 0.15 & 0.15 & 1.55 & 1.27 & 1.19 & 1.55 & 1.43 & 1.27 & 0.92 & 0.94 & 0.91 & 1.23 & 1.1 & 1.05 & 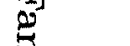 \\
\hline FABACEAE & 0.16 & 0.06 & 0.06 & 1.14 & 0.51 & 0.44 & 0.86 & 0.65 & 0.49 & 0.51 & 0.43 & 0.35 & 0.83 & 0.47 & 0.39 & 3 \\
\hline N.I. & 0.13 & 0.12 & 0.13 & 0.92 & 0.98 & 0.98 & 1.1 & 0.94 & 0.9 & 0.65 & 0.61 & 0.64 & 0.78 & 0.8 & 0.81 & 至 \\
\hline GUTTIFERAE & 0.12 & 0.08 & 0.1 & 0.87 & 0.69 & 0.79 & 1.14 & 0.98 & 0.98 & 0.67 & 0.64 & 0.7 & 0.77 & 0.67 & 0.74 & 战 \\
\hline EUPHORBIACEAE & 0.11 & 0.1 & 0.11 & 0.77 & 0.88 & 0.85 & 1.22 & 1.14 & 1.02 & 0.72 & 0.75 & 0.73 & 0.74 & 0.81 & 0.79 & $D$ \\
\hline MELIACEAE & 0.09 & 0.07 & 0.08 & 0.63 & 0.62 & 0.62 & 1.27 & 1.14 & 1.06 & 0.75 & 0.75 & 0.76 & 0.69 & 0.68 & 0.69 & 0 \\
\hline RUTACEAE & 0.09 & 0.09 & 0.08 & 0.66 & 0.76 & 0.82 & 0.78 & 0.69 & 0.53 & 0.46 & 0.45 & 0.38 & 0.56 & 0.61 & 0.5 & $P$ \\
\hline COMBRETACEAE & 0.12 & 0.05 & 0.06 & 0.88 & 0.46 & 0.48 & 0.41 & 0.24 & 0.24 & 0.24 & 0.16 & 0.18 & 0.56 & 0.31 & 0.33 & 7 \\
\hline ANACARDIACEAE & 0.11 & 0.04 & 0.05 & 0.78 & 0.37 & 0.39 & 0.53 & 0.41 & 0.41 & 0.31 & 0.27 & 0.29 & 0.55 & 0.32 & 0.34 & 0 \\
\hline EBENACEAE & 0.06 & 0.06 & 0.07 & 0.46 & 0.53 & 0.52 & 0.86 & 0.82 & 0.78 & 0.51 & 0.53 & 0.55 & 0.48 & 0.53 & 0.54 & 2 \\
\hline ARALIACEAE & 0.05 & 0.05 & 0.06 & 0.38 & 0.43 & 0.44 & 0.94 & 0.78 & 0.69 & 0.55 & 0.51 & 0.5 & 0.47 & 0.47 & 0.47 & \\
\hline SIMARUBACEAE & 0.03 & 0.03 & 0.03 & 0.22 & 0.27 & 0.27 & 0.57 & 0.57 & 0.49 & 0.34 & 0.37 & 0.35 & 0.28 & 0.32 & 0.31 & \\
\hline APOCYNACEAE & 0.02 & 0.02 & 0.02 & 0.15 & 0.16 & 0.14 & 0.45 & 0.41 & 0.37 & 0.26 & 0.27 & 0.26 & 0.21 & 0.21 & 0.2 & 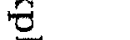 \\
\hline HUMIRIACEAE & 0.03 & 0.03 & 0.03 & 0.24 & 0.27 & 0.27 & 0.29 & 0.24 & 0.24 & 0.17 & 0.16 & 0.18 & 0.21 & 0.22 & 0.22 & 0 \\
\hline CHRYSOBALANACEAE & 0.03 & 0.03 & 0.03 & 0.23 & 0.28 & 0.22 & 0.29 & 0.29 & 0.29 & 0.17 & 0.19 & 0.2 & 0.2 & 0.23 & 0.21 & H \\
\hline VIOLACEAE & 0.03 & 0.03 & 0.04 & 0.22 & 0.26 & 0.27 & 0.24 & 0.24 & 0.24 & 0.14 & 0.16 & 0.18 & 0.18 & 0.21 & 0.22 & $\infty$ \\
\hline MELASTOMATACEAE & 0.02 & 0.01 & 0.01 & 0.11 & 0.11 & 0.09 & 0.29 & 0.24 & 0.16 & 0.17 & 0.16 & 0.12 & 0.14 & 0.14 & 0.1 & ดी \\
\hline SAPINDACEAE & 0.01 & 0.01 & 0.01 & 0.07 & 0.09 & 0.07 & 0.33 & 0.33 & 0.24 & 0.19 & 0.21 & 0.18 & 0.13 & 0.15 & 0.12 & $T$ \\
\hline VOCHYSIACEAE & 0.02 & 0.02 & 0.03 & 0.17 & 0.21 & 0.22 & 0.12 & 0.12 & 0.12 & 0.07 & 0.08 & 0.09 & 0.12 & 0.14 & 0.15 & 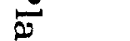 \\
\hline BOMBACACEAE & 0.01 & 0.01 & 0.02 & 0.09 & 0.11 & 0.12 & 0.16 & 0.16 & 0.16 & 0.1 & 0.11 & 0.12 & 0.09 & 0.11 & 0.12 & \\
\hline CELASTRACEAE & 0.01 & 0.01 & 0 & 0.08 & 0.09 & 0.02 & 0.16 & 0.16 & 0.08 & 0.1 & 0.11 & 0.06 & 0.09 & 0.1 & 0.04 & $\stackrel{0}{0}$ \\
\hline OLACACEAE & 0.01 & 0.01 & 0.01 & 0.07 & 0.08 & 0.08 & 0.16 & 0.16 & 0.16 & 0.1 & 0.11 & 0.12 & 0.08 & 0.09 & 0.1 & 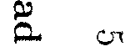 \\
\hline RHAMNACEAE & 0.01 & 0.01 & 0.01 & 0.04 & 0.04 & 0.05 & 0.12 & 0.08 & 0.08 & 0.07 & 0.05 & 0.06 & 0.06 & 0.05 & 0.05 & $\omega$ \\
\hline CARICACEAE & 0.01 & 0.01 & 0.01 & 0.05 & 0.07 & 0.08 & 0.08 & 0.08 & 0.08 & 0.05 & 0.05 & 0.06 & 0.05 & 0.06 & 0.07 & \\
\hline DIDIAPETALACEAE & 0 & 0 & 0 & 0.01 & 0.01 & 0.02 & 0.04 & 0.04 & 0.04 & 0.02 & 0.03 & 0.03 & 0.02 & 0.02 & 0.02 & \\
\hline
\end{tabular}




\begin{tabular}{|c|c|c|c|c|c|c|c|c|c|c|c|c|c|c|c|}
\hline & & $D O A$ & & & DOR & & & $\mathrm{DA}$ & & & $\mathrm{DR}$ & & & IVC & \\
\hline Familias & *1993* & $* 1994 *$ & ${ }^{*} 2000^{*}$ & ${ }^{* 1993^{*}}$ & ${ }^{* 1994 *}$ & ${ }^{*} 2000^{*}$ & ${ }^{* 1993^{*}}$ & ${ }^{*} 1994^{*}$ & ${ }^{*} 2000^{*}$ & ${ }^{* 1993^{*}}$ & ${ }^{*} 1994 *$ & ${ }^{*} 2000^{*}$ & $* 1993^{*}$ & ${ }^{* 1994^{*}}$ & $* 2000^{*}$ \\
\hline SAPOTACEAE & 2.96 & 1.77 & 1.74 & 21.66 & 17.48 & 17.23 & 23.27 & 17.51 & 15.80 & 15.43 & 14.35 & 14.87 & 18.54 & 15.92 & 16.05 \\
\hline LECYTHIDACEAE & 1.74 & 1.41 & 1.45 & 12.74 & 13.93 & 14.35 & 18.49 & 15.06 & 14.20 & 12.26 & 12.35 & 13.37 & 12.50 & 13.14 & 13.86 \\
\hline MIMOSACEAE & 1.52 & 1.20 & 1.07 & 11.12 & 11.87 & 10.59 & 19.67 & 15.80 & 11.47 & 13.04 & 12.95 & 10.80 & $\$ 2.08$ & 12.41 & 10.70 \\
\hline BURSERACEAE & 1.54 & 1.44 & 1.49 & 11.24 & 14.25 & 14.79 & 12.90 & 11.59 & 10.98 & 8.55 & 9.50 & 10.34 & 9.89 & 11.88 & 12.57 \\
\hline CAESALPINACEAE & 1.29 & 0.78 & 0.80 & 9.43 & 7.71 & 7.94 & 14.04 & 10.86 & 9.06 & 9.31 & 8.90 & 8.53 & 9.37 & 8.31 & 8.24 \\
\hline BORAGINACEAE & 0.60 & 0.50 & 0.52 & 4.40 & 4.96 & 5.10 & 13.39 & 11.31 & 10.12 & 8.88 & 9.27 & 9.53 & 6.64 & 7.11 & 7.32 \\
\hline ANNONAGEAE & 0.45 & 0.37 & 0.38 & 3.31 & 3.62 & 3.75 & 9.22 & 7.35 & 6.20 & 8.12 & 6.02 & 5.84 & 4.71 & 4.82 & 4.80 \\
\hline NYCTAGINACEAE & 0.33 & 0.30 & 0.31 & 2.40 & 2.93 & 3.08 & 3.80 & 3.43 & 3.35 & 2.52 & 2.81 & 3.15 & 2.46 & 2.87 & 3.11 \\
\hline CECROPIACEAE & 0.32 & 0.23 & 0.19 & 2.36 & 2.30 & 1.91 & 3.47 & 2.57 & 1.80 & 2.30 & 2.11 & 1.69 & 2.33 & 2.20 & 1.80 \\
\hline LAURACEAE & 0.21 & 0.17 & 0.14 & 1.52 & 1.67 & 1.38 & 4.69 & 3.59 & 2.73 & 3.11 & 2.94 & 2.57 & 2.32 & 2.31 & 1.98 \\
\hline FLACOURTIACEAE & 0.26 & 0.25 & 0.25 & 1.93 & 2.45 & 2.51 & 3.76 & 3.47 & 3.14 & 2.49 & 2.84 & 2.96 & 2.21 & 2.65 & 2.73 \\
\hline MYRISTICACEAE & 0.20 & 0.17 & 0.19 & 1.50 & 1.69 & 1.89 & 3.59 & 3.10 & 2.98 & 2.38 & 2.54 & 2.81 & 1.94 & 2.12 & 2.35 \\
\hline BIGNONIACEAE & 0.28 & 0.14 & 0.15 & 2.07 & 1.35 & 1.50 & 1.80 & 1.27 & 1.10 & 1.19 & 1.04 & 1.04 & 1.63 & 1,19 & 1.27 \\
\hline TILIACEAE & 0.13 & 0.11 & 0.13 & 0.95 & 1.13 & 1.29 & 3.22 & 2.57 & 2.45 & 2.14 & 2.11 & 2.31 & 1.55 & 1.62 & 1.80 \\
\hline CARYOCARACEAE & 0.26 & 0.13 & 0.14 & 1.93 & 1.32 & 1.34 & 1.35 & 1.06 & 0.98 & 0.89 & 0.87 & 0.92 & 1.41 & 1.10 & 1.13 \\
\hline MORACEAE & 0.20 & 0.12 & 0.13 & 1.48 & 1.23 & 1.33 & 1.76 & 1.18 & 1.06 & 1.16 & 0.97 & 1.00 & 1.32 & 1.10 & 1.16 \\
\hline N.I. & 0.18 & 0.12 & 0.13 & 1.32 & 1.19 & 1.30 & 1.88 & 1.55 & 1.43 & 1.24 & 1.27 & 1.35 & 1.28 & 1.23 & 1.32 \\
\hline FABACEAE & 0.22 & 0.12 & 0.12 & 1.62 & 1.19 & 1.20 & 1.35 & 0.98 & 0.86 & 0.89 & 0.80 & 0.81 & 1.26 & 1.00 & 1.00 \\
\hline EUPHORBIACEAE & 0.11 & 0.10 & 0.09 & 0.80 & 0.98 & 0.93 & 1.18 & 1.02 & 0.90 & 0.78 & 0.84 & 0.85 & 0.79 & 0.91 & 0.89 \\
\hline STERCULIACEAE & 0.05 & 0.04 & 0.04 & 0.38 & 0.38 & 0.38 & 1.43 & 1.14 & 0.94 & 0.95 & 0.94 & 0.88 & 0.67 & 0.66 & 0.63 \\
\hline RUTACEAE & 0.10 & 0.08 & 0.05 & 0.70 & 0.83 & 0.53 & 0.82 & 0.73 & 0.45 & 0.54 & 0.60 & 0.42 & 0.62 & 0.71 & 0.48 \\
\hline ARALIACEAE & 0.08 & 0.06 & 0.07 & 0.60 & 0.64 & 0.74 & 0.82 & 0.65 & 0.61 & 0.54 & 0.54 & 0.58 & 0.57 & 0.59 & 0.66 \\
\hline APOCYNACEAE & 0.11 & 0.11 & 0.11 & 0.80 & 1.09 & 1.07 & 0.45 & 0.45 & 0.33 & 0.30 & 0.37 & 0.31 & 0.55 & 0.73 & 0.69 \\
\hline GUTTIFERAE & 0.07 & 0.05 & 0.05 & 0.49 & 0.47 & 0.50 & 0.69 & 0.49 & 0.45 & 0.46 & 0.40 & 0.42 & 0.48 & 0.44 & 0.46 \\
\hline BOMBACACEAE & 0.06 & 0.06 & 0.07 & 0.47 & 0.57 & 0.65 & 0.73 & 0.61 & 0.61 & 0.49 & 0.50 & 0.58 & 0.48 & 0.53 & 0.61 \\
\hline ANACARDIACEAE & 0.09 & 0.03 & 0.03 & 0.69 & 0.26 & 0.27 & 0.29 & 0.20 & 0.12 & 0.19 & 0.17 & 0.12 & 0.44 & 0.22 & 0.19 \\
\hline HUMIRIACEAE & 0.05 & 0.05 & 0.05 & 0.39 & 0.50 & 0.45 & 0.53 & 0.49 & 0.41 & 0.35 & 0.40 & 0.38 & 0.37 & 0.45 & 0.42 \\
\hline VIOLACEAE & 0.06 & 0.06 & 0.06 & 0.44 & 0.60 & 0.64 & 0.41 & 0.41 & 0.37 & 0.27 & 0.33 & 0.35 & 0.36 & 0.47 & 0.49 \\
\hline COMBRETACEAE & 0.06 & 0.03 & 0.03 & 0.42 & 0.26 & 0.27 & 0.24 & 0.16 & 0.12 & 0.16 & 0.13 & 0.12 & 0.29 & 0.20 & 0.19 \\
\hline SIMARUBACEAE & 0.02 & 0.02 & 0.02 & 0.14 & 0.17 & 0.21 & 0.49 & 0.41 & 0.37 & 0.32 & 0.33 & 0.35 & 0.23 & 0.25 & 0.28 \\
\hline MELASTOMATACEAE & 0.02 & 0.02 & 0.02 & 0.15 & 0.20 & 0.18 & 0.29 & 0.29 & 0.24 & 0.19 & 0.23 & 0.23 & 0.17 & 0.22 & 0.21 \\
\hline VOCHYSIACEAE & 0.03 & 0.03 & 0.03 & 0.21 & 0.29 & 0.30 & 0.16 & 0.16 & 0.16 & 0.11 & 0.13 & 0.15 & 0.16 & 0.23 & 0.23 \\
\hline EBENACEAE & 0.02 & 0.02 & 0.02 & 0.14 & 0.16 & 0.18 & 0.24 & 0.20 & 0.20 & 0.16 & 0.17 & 0.19 & 0.15 & 0.17 & 0.19 \\
\hline CARICACEAE & 0.02 & 0.02 & 0.01 & 0.14 & 0.19 & 0.09 & 0.16 & 0.16 & 0.08 & 0.11 & 0.13 & 0.08 & 0.12 & 0.16 & 0.09 \\
\hline MELIACEAE & 0.01 & 0.00 & 0.00 & 0.04 & 0.04 & 0.01 & 0.16 & 0.08 & 0.04 & 0.11 & 0.07 & 0.04 & 0.07 & 0.06 & 0.02 \\
\hline CELASTRACEAE & 0.00 & 0.00 & 0.01 & 0.03 & 0.04 & 0.06 & 0.04 & 0.04 & 0.04 & 0.03 & 0.03 & 0.04 & 0.03 & 0.04 & 0.05 \\
\hline MALPIGHIACEAE & 0.00 & 0.00 & 0.00 & 0.02 & 0.03 & 0.04 & 0.04 & 0.04 & 0.04 & 0.03 & 0.03 & 0.04 & 0.02 & 0.03 & 0.04 \\
\hline
\end{tabular}




\section{REFERÊNCIAS BIBLIOGRÁFICAS}

ALMEIDA,O.T.; UHL,C. Planejamento do uso do solo do município de Paragominas utilizando dados econômicos e ecológicos. Serie Amazonia, n.9, p. $1-46,1997$.

AMARO, M. A. Inventário florestal do projeto de assentamento extrativista São Luis do Remanso. In: CONGRESSO FLORESTAL BRASILEIRO, 7., Curitiba, 1993. São Paulo: SBS/SBEF, 1993. v.1, p.367-71.

ATTIWILL, P.M. The disturbance of forest ecosystem: The ecological basis for conservative management. Forest Ecology and Management, v. 63, p. 247 $270,1994$.

BARRETO, P. ; AMARAL, P.; VIDAL, E.; UHL,C. Custo e benefícios do manejo florestal para produção de madeira na Amazônia oriental. Serie Amazonia, n.10, p. $1-46,1998$.

BARROS, A. C.; UHL, C. Padrões, problemas e potencial da extração de madereira ao longo do rio Amazonas e do estuário. Serie Amazônica, 4, p. 1-41, 1997.

BARROS, A. V.; BARROS, P. L. C.; SILVA, L. C. B. Análise fitossociológica de uma floresta situada em Curuá-Una - Pará. Revista Ciências Agrárias, n.34, p. $9-36,2000$.

BAZZAZ, F. A.; PICKETT, S. T. A. Ecofisiologia de la sucesion tropical: Una revision comparativa. Cronica Forestal y del Medio Ambiente, v.6, p. 1 - 27, 1988. 
BRASIL. Ministério do Meio Ambiente. Convenção sobre diversidade biológica. http://www.mma.gov.br/chm/dpreambl.html. (17 abr. 2000).

BUSH, M. B. Amazonian conservation in a changing world. Biological Conservation, v. 76, n. 3, p. $219-228,1996$.

CAIN, S. A.; CASTRO, G. M. O. Manual of vegetation analysis year, New York : Harper, 1959, 325 p.

CORRÊA, A.A.M. Expansão da degradação do solo e sobrevivência da população. Boletim Informativo da Fundação Brasileira para a Conservação da Natureza, v. 23, p.13-29, 1988.

CRAWLEY, M. J. The structure of plant communities. In: CRAWLEY, M. J. (Ed.), Plant ecology, 2. ed. Oxford: Blackwell Science, 1997, p. 475 - 531.

FEARNSIDE, P. M. Migração, colonização e meio ambiente: O potencial dos ecossistemas amazônicos. In: VAL, A. L.; FIGLIUOLO, R.; FELDBERG, E. Bases Científicas para estratégias de preservação e desenvolvimento da Amazônia, Manaus: INPA, 19993, v. 2, p. $249-267$.

FELFILI, J.M. ; VENTUROLI, F. Tópicos de análise de vegetação. Comunicações Técnicas Florestais, v.2, n. 3, p. $1-34,2000$.

FERREIRA, L.V. ; PRANCE, G.T. Structure and species richness of low-diversity floodplain forest on the rio Tapaj'os, eastern Amazonia, Brazil. Biodiversity and Conservation, v. 7, p. $585-596,1998$. 
FINOL, U. H. Nuevos parametros a consideraise en la analisis estructural de las selvas virgenes tropicales. Revista Forestal Venezoelana, v. 14, n. 21, p. $29-$ $42,1971$.

FUJISAKA, S.; BELL, W.; THOMAS, N.; HURTADO, L.; CRAWFORD, E. Slash-and-burn agriculture, conversion to pasture, and deforestation in two brazilian Amazon colonies. Agriculture, Ecosystems and Environment, v. 59, n. $1-2$, p. $115-130,1996$.

GAINES,W.L.; HARROD,R.J.; LEHMKUHL,J.F. Monitoring biodiversity: quantification and interpretation. USDA Forest Service PNW General Technical Report, n.443, p. 1-27, 1999.

GASH, J.; NOBRE, C.; ROBERTS, J.; VICTORIA, R. Amazon deforestation and climate. London: Wiley, 1996.629p.

HIGUCHI, N.; SANTOS, J.; JARDIM, F. C. S. Tamanho de parcela amostral para inventários florestais. Acta Amazonica, v.12, n.1, p. 91 -103, 1982.

HIGUCHI, N.; SANTOS, J.; RIBEIRO, R. J. and FREITAS, J. V.; VIEIRA, G.; COIC, A. MINETTE, L. J. Crescimento e incremento de uma Floresta Amazônica de terra-firme manejada experimentalmente. In: HIGUCHI, N.; SANTOS, J.; FERRAZ, J. B. S.; ANTONY, L.; LUIZÃO, F.; LUIZÃO, R.; BIOT, Y.; HUNTER, I.; PROCTOR, J.; ROSSI, S. (Ed.) Biomassa e nutrientes florestais: relatório final, Manaus: INPA, DFID, 1997. p. 88-132. 
HELLMANN, J. J.; FOWLER, G. W. Bias, precision and accurancy of four measures of species richness. Ecological Applications, v. 9, n. 3, p. $824-834$, 1999.

HUSCH,B.; MILLER,C.I.; BEERS,T.W. Forest mensuration. 3 ed. New York: Ronald Press, 1982. 412 p.

JANOS, I.; PAPP, L. A link between ecological diversity indices and measures of Biodiversity. Ecological Modelling, n. 130, p. 151 - 156, 2000.

JOHNS, J.S.; BARRETO, P.; UHL, C. Logging damage during planned and unplanned logging operations in the eastern Amazon. Forest Ecology and Management. v. 89, n. 1/3, p. $59-77,1996$.

KRAUSE, G. A. A subversão ambiental. Ciência Hoje, v. 20, n. 120, p. 64 - 71, 1996.

KORNING, J.; THOMSEN, K.; OLLGAARD, B. Composition structure of a species rich amazonian rain forest obtained by two different sample methods. Nordic Journal of Botany, v. 11, n. 1, p. $103-110,1991$.

LAMPRECHT, H. Silvicultura nos trópicos: ecossistemas florestais e respectivas espécies arbóreas, possibilidades e métodos de aproveitamento sustentado. Eschborn: GTZ, 1990. 343p.

LEONEL, M. A morte social dos rios: conflito, natureza e cultura na Amazônia. São Paulo: Instituto de Antropologia e Meio Ambiente; FAPESP, 1998. 263 p.

LÉVÊQUE, C. A. A biodiversidade. Trad. de V. Mermelstein. São Carlos: EDUSC, 1999. 246 p. 
LORENZO,J.S.; GRIFFITH,J.J.; JUCKSCH,I.; SOUZA,A.L.; REIS,M.G.F.; VALE,A.B. A fitossociologia para recuperar área de lavra. Ambiente, v.8, n.1, p.26-34, 1994.

LOUREIRO,V.R. Amazônia: historia e perspectivas, reflexões sobre a questão. Para Desenvolvimento. v. 26, p. 3-24, 1990.

MAGURRAN, A. E. Ecological diversity and its measurement. Princeton: Princeton University Press, 1988. 179 p.

MARTINI, A.M. Z.; ROSA, N. D.; UHL, C. An attempt to predict which amazonian tree species may be threatened by logging activities. Environmental Conservation, v. 22, n. 1, p. $152-162,1994$.

MCMINN, J. W. Biological diversity research: An analysis. USDA Forest Service SE General Technical Report, n. 71, p. 1-7, 1991.

MONTOYA MAQUIN, J. M. El acuerdo de Yangambi (1956) como base para una nomenclatura de tipos de vegetacion en el tropico americano. Turrialba, v. 17, n. 2, p. $197-207,1966$.

MUELLER-DOMBOIS,D; ELLENBERG,H. Aims and methods of vegetation ecology. New York: John Wiley, 1974. 547p.

MUNIZ, F. H.; CESAR, O.; MONTEIRO, R. Aspectos florísticos quantitativos e comparativos da vegetação arbórea da reserva florestal do Sacavém, São Luis, Maranhão (Brasil). Acta Amazonica, v. 24, n. 3 - 4, p.189-218, 1994. 
NAEEM, S; THOMPSON, L. J.; LAWER, S.P.; LAWTON, J. H.; WOODFIN, R. M. Declining biodiversity can alter the performance of ecosystems. Nature, v. 368 , n. 6473 , p. $734-737,1994$.

NOBRE, C. A.; GASH, J. Desmatamento muda clima da Amazônia. Ciência Hoje, v. 22 , n. 188, p. $32-41,1997$.

OLIVEIRA, A. A.; MORI, S. A. A Central Amazonian terra firme forest. I. High tree species richness on poor soils. Biodiversity and Conservation, v.9, n.8, p. $1219-1244,1999$.

OWUBAH, C. E.; LE MASTER, D. C.; BOWKER, J. M.; LEE, J. G. Forest tenure systems and sustainable forest management: The case of Ghana. Forest Ecology and Management. v. 149, p. $253-264,2001$.

PÉLLICO NETTO, S.; BRENA, D.A. Inventário florestal. Curitiba: Os autores, 1997. v.1.

PERES, C. A. Paving the way to the future of Amazonia. Trends in Ecology and Evolution, v. 16, n. 5, p. $217-219,2001$.

PIELOU, E. C. Biodiversity versus old-style measuring biodiversity for conservation. In: IUFRO SYMPOSIUM HELD AT CHIANG MAI, Thailand, 1994. Thailand: IUFRO; SPDC, 1994, v. 1, p. 5-17.

PINTO-COELHO, R. M. Fundamentos da ecologia. Porto Alegre: Artes Médicas Sul, 2000. 252p.

PIRES-O'BRIEN, M. J.; O'BRIEN, C. M. Ecologia e modelamento de florestas tropicais. Belém: FCAP, 1995. 400p. 
PITKÄNEN, S. The use of diversity indices to assess the diversity of vegetation in managed boreal forests. Forest Ecology and Management, v. 112, p. 121 - 137, 1998.

RADAMBRASIL. Folha \{SA\}.22 - Belém, Rio de Janeiro, 1974. v. 5.

REBOUÇAS, A.C. Panoramas da degradação do ar, da água doce e da terra no Brasil. São Paulo: IEA; USP; Rio de Janeiro: Academia Brasileira de Ciências, 1997. $150 \mathrm{p}$.

RIBEIRO, R. J.; HIGUCHI, N.; SANTOS, J.; AZEVEDO, C. P. Estudo fitossociológico nas regiões de Carajás e Marabá - Pará, Brasil. Acta Amazonica, v. 29, n. 2, p. $207-222,1999$.

ROCK, M. T. The stork, the plow, rural social structure and tropical deforestation in poor countries? Ecological Economics, v. 18, n. 2, p. 113 - 131, 1996.

RODRIGUES, R. R. Formação florestal: métodos fitossociológicos mais usados. Casa da Agricultura, n. 10, p. $12-18,1988$.

ROUTLEDGE, R. D. Measurements and estimates. In: SIT, V.; TAYLOR, B. Statistical methods for adaptive management studies. British Columbia: Ministry of Forests Research Program, 1998. p. 55 - 68.

SAMANEZ MERCADO,R. Notas sobre la economia forestal Amazonica regional. Floresta e Ambiente, v. 1, p. 151 - 157, 1994.

SCHNEIDER, R. R.; ARIMA, E.; VERÍSSIMO, A.; BARRETO, P.; SOUZA Jr., C. Amazônia sustentável: limitantes e oportunidades para o desenvolvimento rural. Brasília: Banco Mundial; Imazon, 2000. 58 p. 
SILVA, E. J. V. Impactos da exploração madereira predatória e planejada sobre o crescimento e diversidade de espécies arbóreas na Amazônia oriental. Piracicaba, 1998. 81p. Dissertação (Mestrado) - Escola Superior de Agricultura "Luis de Queiroz", Universidade de São Paulo.

SILVA,N.N. Manejo de florestas de terra-firme da Amazônia brasileira. Documentos EMBRAPA/CNPF, v. 34, p. 59-96, 1997.

VERÍSSIMO, A.; BARRETO, P.; TARIFA, R.; UHL, C. Extration of a High Value Resource from Amazonia: The Case of Mahogany. Forest Ecology and Management. v. 72, p. $39-60,1995$,

VERÍSSIMO, A.; BARRETO, P.; MATTOS, M.; TARIFA, R.; UHL, C. Logging impacts and prospects for sustainable forest management in an old Amazonian frontier: The case of Paragominas. Forest Ecology and Management, v. 55, n.1-4, p. $169-199,1992$.

VIDAL, E.; VIANA, V.; BATISTA, J. L. F. Efeitos da exploração madereira predatória e planejada sobre a diversidade de espécies na Amazônia oriental. Revista Árvore, v. 22, n. 4, p. 503-520, 1998.

WALKER, R.; MORAN, E.; ANSELIN, L. Deforestation and cattle ranching in the brazilian Amazon: external capital and household processes, World Development, v. 28, n. 4, p. $683-699,2000$.

WHITE, P.S.; PICKETT, S.T.A. Natural disturbance and patch dynamics: An introduction. In: PICKETT, S.T.A.; WHITE, P.S. (Ed.) The ecology of natural disturbance and patch dynamics. Orlando: Academic Press, 1985. p. 3 - 13. 